Review

\title{
Lysophosphatidic Acid Receptors: Biochemical and Clinical Implications in Different Diseases
}

\author{
Hongjiao Xiang, Yifei Lu, Mingmei Shao, Tao $\mathrm{Wu}^{凶}$ \\ Center of Chinese Medical Therapy and Systems Biology, Institute of Interdisciplinary Integrative Medicine Research, Shanghai University of Traditional \\ Chinese Medicine, Shanghai 201203, China \\ $\triangle$ Corresponding author: Tao Wu, PhD, Assistant Professor, Center of Chinese Medical Therapy and Systems Biology, Institute of Interdisciplinary Integrative \\ Medicine Research, Shanghai University of Traditional Chinese Medicine, Shanghai, China. E-mail: tw827@shutcm.edu.cn or wutao001827@163.com. Telephone: \\ +86-21-51322748; Fax: +86-21-51322748. \\ (c) The author(s). This is an open access article distributed under the terms of the Creative Commons Attribution License (https://creativecommons.org/licenses/by/4.0/). \\ See http://ivyspring.com/terms for full terms and conditions.
}

Received: 2019.11.05; Accepted: 2020.02.25; Published: 2020.03.15

\begin{abstract}
Lysophosphatidic acid (LPA, 1-acyl-2-hemolytic-sn-glycerol-3-phosphate) extracted from membrane phospholipid is a kind of simple bioactive glycophospholipid, which has many biological functions such as stimulating cell multiplication, cytoskeleton recombination, cell survival, drug-fast, synthesis of DNA and ion transport. Current studies have shown that six G-coupled protein receptors (LPAR1-6) can be activated by LPA. They stimulate a variety of signal transduction pathways through heterotrimeric G-proteins (such as Gal2/13, Gaq/11, Gai/o and GaS). LPA and its receptors play vital roles in cancers, nervous system diseases, cardiovascular diseases, liver diseases, metabolic diseases, etc. In this article, we discussed the structure of LPA receptors and elucidated their functions in various diseases, in order to better understand them and point out new therapeutic schemes for them.
\end{abstract}

Key words: lysophosphatidic acid, LPAR, structure, physiology and pathology, cancer

\section{Introduction}

Lysophosphatidic acid (LPA, 1-acyl-2-hemolyticsn-glycerin-3-phosphate), a small glycerophosphatidic acid, widely exists in human body. It has many different biological functions, such as promoting cell growth, differentiation, movement, survival and cytoskeleton morphological change [1]. LPA combines with a variety of known G-protein coupled receptors (GPCRs) to perform a wide range of biological functions.

The six lysophosphatidic acid receptors (LPAR) currently known can be subdivided according to their homology. $\mathrm{LPA}_{1-3}$ receptor belongs to the endothelium differentiation gene (EDG) receptor, which has $50-57 \%$ amino acid identity with each other, while $\mathrm{LPA}_{4-6}$ receptor, which is a non EDG receptor with a long phylogenetic distance, has $35-55 \%$ amino acid identity with each other [2,3]. Since the LPA receptors currently known are all G-protein coupled receptor families, they are all rhodopsin-like and have seven transmembrane domains, three extracellular loops (extracellular
loop-ECL1, ECL2, ECL3) and three intracellular loops (intracellular loop-ICL1, ICL2, ICL3). It also has an $\mathrm{N}$-terminus within the cell and a C-terminus outside the cell [4]. At least two Ga subunits (Ga12/13, Gaq/11, Gai/o and GaS) are used by the LPA receptors to signal, thereby activating different downstream pathways, and under different environments and cell types produce different results [5]. Numerous studies have shown that the role of LPA and its receptors is crucial in neurological diseases, tumors, metabolic diseases, liver diseases and cardiovascular diseases [6,7]. In recent years, the role of LPA and its receptors in diseases has been paid more and more attention, and research into their mechanisms to find new disease treatment programs has become the focus of current research.

In this review, we hope to provide some new ideas and directions for the prevention and treatment of related diseases by summarizing the different functions of LPA receptors in different diseases. 


\section{Structure of lysophosphatidic acid receptor}

\section{LPAR 1}

LPAR1, the earliest LPA receptor, was found in the neuroproliferative ventricular zone (VZ), superficial marginal zone, and meninges in a brain study in 1996 and identified as a receptor mediating LPA action [8]. $\mathrm{LPA}_{1}$ is widely expressed in various tissues and organs of human body, in which the mRNA levels in brain, heart, colon, small intestine and placenta are higher, but relatively lower in other organs and tissues [9]. LPAR1, a $41 \mathrm{kDa}$ protein, consists of 364 amino acids. Its human chromosome gene is located on chromosome 9 (9q31.3), and has 7 transmembrane domains like other LPA receptors (Figure 1) [10]. Three extracellular loops and three intracellular loops were formed by patterning 7 times on the plasma membrane. The transmembrane span III (TMIII) and transmembrane spanning V (TMV) and transmembrane spanning VII (TMVII) linkages to ECL1 and ECL2 are key regions for LPA binding to $\mathrm{LPA}_{1}$. The activation and desensitization of intracellular signals is associated with the ICL2 region, while the smallest ICL1 allows the cytoplasmic organelle to correctly process the receptor and express it on the cell surface. Among several intracellular and extracellular loops, ICL3, which has 33 amino acids, is the largest. It is a key region for $\mathrm{LPA}_{1}$ signal transduction and attenuation [11]. It was also found that LPA1 preferred to receive ligands in extracellular environment [12]. The receptor activates downstream pathways such as Akt, rho, mitogen-activated protein kinase (MAPK) and phospholipase C (PLC) by coupling with Gai/o, Gaq/11 and Ga12/13. LPA mediates a great diversity of functions through $\mathrm{LPA}_{1}$ coupled to the $G$ protein, including cell survival, cell proliferation, cell adhesion, cell migration, cytoskeletal changes, $\mathrm{Ca}^{2+}$ mobilization, immune function, and myelination [5]. Such as promoting astrocyte proliferation and neuronal differentiation, proliferation of oligodendrocytes and smooth muscle cells, migration and anti-apoptosis of Schwann cells, mineralization and osteogenic transformation of valve interstitial cell (VIC) $[13,14]$. Approximately $50 \%$ of $\mathrm{LPA}_{1}$-deficient mice presented neonatal mortality, which may be due to the lack of olfactory agent detection or olfactory processing in these mice, resulting in their inability to locate nipples for breastfeeding. These mice also showed changes characterized by nose shrinkage, eye spacing enlargement, cerebral cortex development changes and weight loss. Besides, some mice also experienced frontal cranial hemorrhage [5].

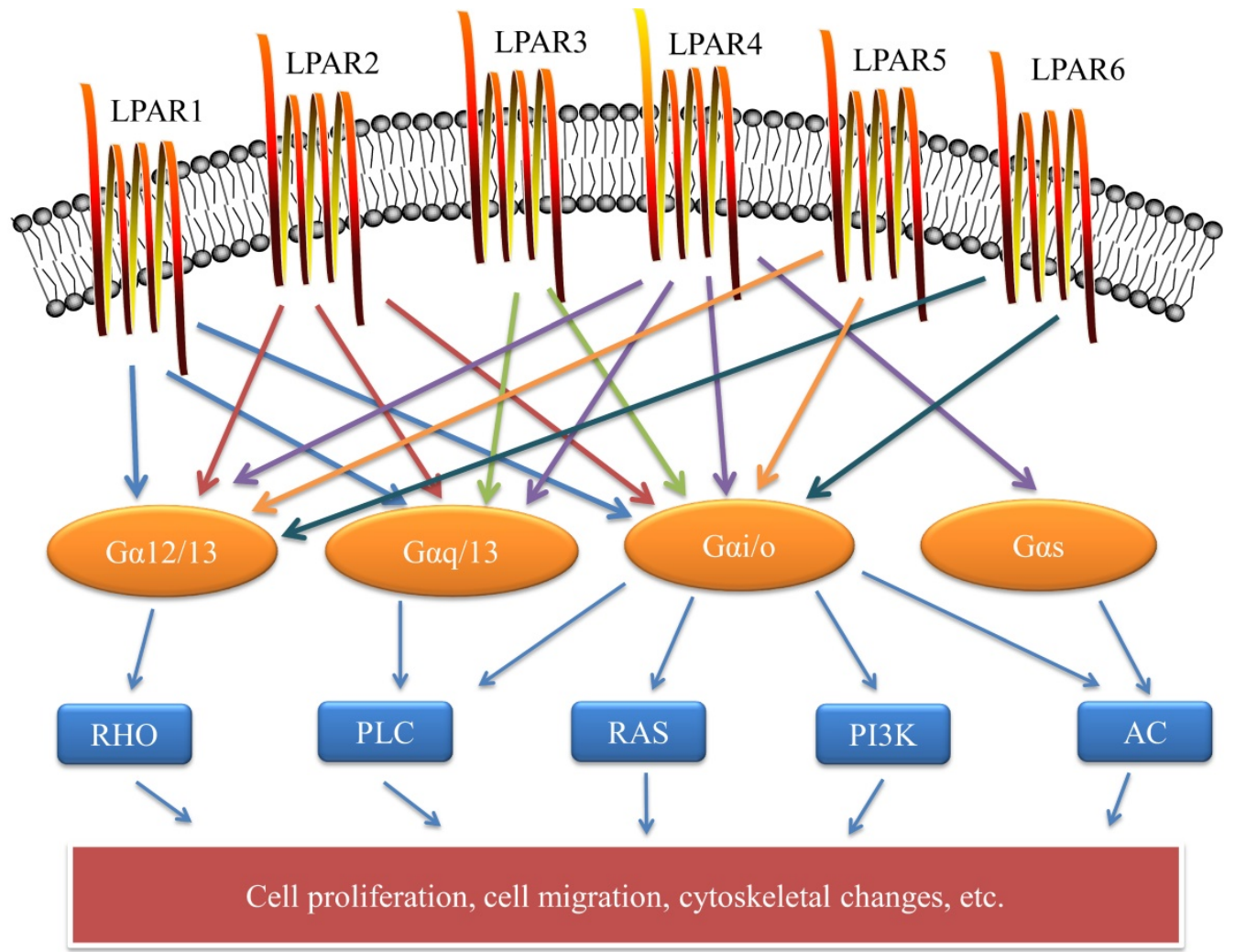

Figure 1. Cell surface LPA receptors and their downstream signaling pathways. LPA signaling is mediated through six known G protein-coupled receptors. The LPA receptor is a 7-TM structure that is coupled to at least two G protein family members to activate downstream pathways that mediate a variety of cellular responses. These include cell proliferation, cell migration, and cytoskeletal changes. LPAR: lysophosphatidic acid receptor; RHO: rho protein; PLC: phospholipase C; RAS: ras protein; PI3K: phosphatidylinositol 3-kinase; AC: adenylyl cyclase. 


\section{LPAR2}

$\mathrm{LPA}_{2}$ was identified from a gene library homology search of orphan GPCR genes, which has approximately $60 \%$ amino acid similarity to $\mathrm{LPA}_{1}[15]$. LPAR2 is a receptor encoding 348 amino acids with a molecular weight of about $39 \mathrm{kDa}$. The human gene is located on chromosome 9 (19p12) [9]. The coding region of the mouse $\mathrm{LPA}_{2}$ gene containing three exons is located in exons 2 and 3 [16]. $\mathrm{LPA}_{2}$ receptor mRNA expression in kidney, uterus, testis and leukocytes was higher than that in thymus, pancreas and spleen. $\mathrm{LPA}_{2}$ is the same as LPA 1 , is also coupled with Gai/o, Gaq/11 and Ga12/13 in the heterotrimeric $G$ protein family. In turn, through Ras, MAPK, phosphatidylinositol 3-kinase (PI3K), Rac, PLC, diacylglycerol (DG) and Rho and other downstream molecules transmit signals that mediate cell survival and cell migration [5,9]. The PSD-95/DlgA/ZO-1 (PDZ) binding motif is located at the carboxy terminus of the $\mathrm{LPA}_{2}$ receptor and interacts with a variety of PDZ scaffold proteins. These scaffold proteins include $\mathrm{Na}^{+} / \mathrm{H}^{+}$exchange regulatory factor-1 (NHERF-1), $\mathrm{Na}^{+} / \mathrm{H}^{+}$exchange regulatory factor-2 (NHERF-2), inverted orientation-2 (MAGI-2), inverted orientation-3 (MAGI-3), neurabin, PDZ-RhoGEF (PRG) and leukemia-associated Rho GEF (LARG) proteins. The interaction between NHERF-2 and LPA 2 enhanced LPA mediated cell proliferation and cell migration, while the interaction between MAGI-3 and $\mathrm{LPA}_{2}$ resulted in the opposite effect of NHERF-2. MAGI-3 had a negative regulatory effect on $\mathrm{LPA}_{2}$ mediated cell function [17]. Studies have shown that spatial organization of PDZ motif-mediated $\mathrm{LPA}_{2}$ receptor macromolecular complex assembly mediates LPA gradient sensing in fibroblasts [18]. LPA mediates anti-apoptosis of cells through $\mathrm{LPA}_{2}$ receptor, and the damage repair effect of $\mathrm{LPA}_{2}$ receptor on DNA can protect cells from radiation to some extent [19]. There was no apparent phenotypic abnormality in $\mathrm{LPA}_{2}$-deficient mice, but in $\mathrm{LPA}_{1}$ and $\mathrm{LPA}_{2}$-deficient mice, the incidence of frontal lobe hematoma increased during perinatal period [9].

\section{LPAR3}

$\mathrm{LPA}_{3}$ was discovered similarly to $\mathrm{LPA}_{2}$ and cloned by a cloning method based on degenerate polymerase chain reaction [20]. LPAR3, a human chromosomal gene, is located at 1p22.3-p31.1 and consists of 353 amino acids, with a molecular weight of approximately $40 \mathrm{kDa}$. $\mathrm{LPA}_{3}$, located on the $\mathrm{X}$ chromosome, is similar to $\mathrm{LPA}_{1}$ and $\mathrm{LPA}_{2}$ in that it has about $50 \%$ amino acids $[9,21]$. LPAR3 is coupled to Gai/o and Gaq of the heterotrimeric G protein, mediating PLC activation, $\mathrm{Ca}^{2+}$ mobilization, inhibition and activation of adenylate cyclase (AC), and protein kinase activation that mediates mitogen activation [22]. The mRNA level of LPAR3 is higher in human heart, lung, pancreas, brain, testis, prostate and ovary. However, in mice, the mRNA levels of LPAR3 in testis, kidney, thymus, small intestine, lung, stomach and brain are higher [9]. Under the action of $\mathrm{LPA}_{3}$, immature mouse dendritic cells can be chemotaxis to LPA [23]. The $\mathrm{LPA}_{3}$ receptor can also participate in the mobilization and recruitment of smooth muscle progenitor cells (SPC) and mediate the development of central post-stroke pain (CPSP) along with the $\mathrm{LPA}_{1}$ receptor $[14,24]$. In contrast to mice lacking $\mathrm{LPA}_{1}$ and $\mathrm{LPA}_{2}$, the absence of $\mathrm{LPA}_{3}$ resulted in delayed embryo implantation and changes in embryo spacing, which dramatically reduces embryo crowding and litter size. The effect of $\mathrm{LPA}_{3}$ on embryo implantation is related to cyclooxygenase-2 (COX-2) and its derived prostacyclin (PGI2), as the lack of COX-2 leads to reproductive failure in multiple female mice $[25,26]$. The lack of $\mathrm{LPA}_{3}$ receptor alone did not show a definite change in male reproduction, but the $\mathrm{LPA}_{1}$ receptor, $\mathrm{LPA}_{2}$ receptor and $\mathrm{LPA}_{3}$ receptor combined with defective male mice showed decreased germ cell survival and increased azoospermia prevalence [26]. The above studies suggest that $\mathrm{LPA}_{3}$ is closely related to reproduction.

\section{LPAR4}

The $\mathrm{LPA}_{4}$ receptor discovered by ligand screening differs from the amino acid sequence of $\mathrm{LPA}_{1-3}$. Its amino acid similarity with LPAR1-3 is only $20-24 \% . \mathrm{LPA}_{4}$ is structurally distinct from previously identified EDG family receptors $\left(\mathrm{LPA}_{1}, \mathrm{LPA}_{2}, \mathrm{LPA}_{3}\right)$ and more similar to $\mathrm{P} 2 \mathrm{Y}$ purinergic receptors [27]. In humans, the 370 amino acid $\mathrm{LPA}_{4}$ gene is located in the q13-q21.1 region of the $X$ chromosome and contains a $1113 \mathrm{bp}$ intron-free open reading frame with a molecular weight of about $40 \mathrm{kDa}[9,27]$. LPAR4 mRNA levels are higher in mouse skin, heart, ovary, thymus, developing brain and embryonic fibroblasts, and levels in the ovary are more pronounced [7,9]. $\mathrm{LPA}_{4}$ binds primarily to Gaq, Gai, Ga12/13 and Gas to activate downstream pathways [28]. $\mathrm{LPA}_{4}$ induces intracellular cyclic adenosine monophosphate (cAMP) accumulation by Gas [27], cell aggregation and adhesion by $\mathrm{N}$-cadherin [29], as well as neurite contraction and stress fiber formation by activating the Rho/ROCK pathway [30]. Other studies have shown that it can affect the differentiation of immortalized hippocampal progenitor cells [31]. In contrast to the $\mathrm{LPA}_{1}$ receptor, LPA-mediated migration and invasion of the cell are inhibited by the $\mathrm{LPA}_{4}$ receptor; for example, studies have found that continued progression of rat 
neuroblastoma and human colon cancer can be inhibited by $\mathrm{LPA}_{4}$ [32,33]. Different degrees of subcutaneous hemorrhage and vasodilation, impaired vascular endothelial cell wall cell coverage, and lymphatic dysplasia were observed in $\mathrm{LPA}_{4}$-deficient mouse embryos [34]. It indicates that LPA4 receptor can promote angiogenesis and vascular development. In addition, the regulatory factor Yes-associated protein (YAP) and the transcriptional coactivator with PDZ-binding motif (TAZ) can also be activated by $\mathrm{LPA}_{4} / \mathrm{LPA}_{6}$ via the Ga12/Ga13 signaling pathway [35]. YAP and TAZ can accelerate the progression of cancer by promoting the proliferation and migration of cancer cells, such as accelerating liver cancer, bladder cancer and lung cancer [36-38]. Also, the volume, number and thickness of trabeculae increased in adult $\mathrm{LPA}_{4}{ }^{-/}$-mice, contrary to those observed in $\mathrm{LPA}_{1}-$-mice, suggesting that $\mathrm{LPA}_{4}$ has a negative regulatory effect on bone formation and can counteract $\mathrm{LPA}_{1}$-induced bone formation [39].

\section{LPAR5}

As the fifth reported LPA receptor, $\mathrm{LPA}_{5}$ was identified as a member of the LPA receptor by using reverse transcription in an unbiased screening method. LPAR5 shares 35\% homology with LPAR4, but with LPAR1-3 only 22\% homology [40]. The molecular weight of LPAR5 consisting of 372 amino acids is about $41 \mathrm{kDa}$. The human gene is located at 12p13.31. Large amounts of LPAR5 are expressed in the spleen, small intestine, and colon, but are relatively low in most other tissues [7,40,41]. LPAR5 has multiple endogenous ligands including LPA, geranylgeranyl diphosphate (GGPP), farnesyl monophosphate, farnesyl pyrophosphate, $\mathrm{N}$-arachidonoyl Glycine alkyl glycerophosphate and cyclic phosphatidic acid [41,42]. Stress fiber formation and neurite contraction are associated with the LPA-LPA $_{5}-$ Ga12/Ga13 pathway, whereas increased intracellular calcium levels and CAMP accumulation are associated with the LPA-LPA ${ }_{5}-\mathrm{Gaq}$ pathway $[7,9$, 40]. LPA binds to $\mathrm{LPA}_{5}$ expressed on mouse and human $\mathrm{CD}^{+} \mathrm{T}$ cells, inhibited $\mathrm{T}$ cell antigen receptor (TCR)-induced intracellular calcium mobilization, extracellular regulated protein kinases (ERK) activation and Nur77 expression, thereby reduced granular exocytosis and cytotoxicity [43]. $\mathrm{LPA}_{5}$ is also expressed in the spinal cord and dorsal root ganglia (DRG) and can promote the signaling of extensive pain in the spinal cord [42]. In intestinal epithelium, $\mathrm{LPA}_{5}$ is the primary LPA receptor regulating $\mathrm{Na}^{+} / \mathrm{H}^{+}$ Exchanger 3 (NHE3). It co-expressed with NHERF-2, induces $\mathrm{Na}^{+}$-dependent water absorption, and recruits NHE3 to intestinal microvilli $[41,44]$. Studies have shown that the transmission of pruritus signals caused by LPA is mainly transmitted through LPA, PLD; transient receptor potential vanilloid 1 (TRPV1) and transient receptor potential ankyrin 1 (TRPA1) [45]. Whether $\mathrm{LPA}_{5}$ deficiency leads to disease-related changes is currently unclear.

\section{LPAR6}

As the sixth prion-coupling receptor for LPA; LPAR6, formerly known as P2Y5, was recognized as an LPA receptor in 2008 and is thought to be closely related to hair growth. The location of LPAR6 on chromosome is 13 (13q14), which encodes 344 amino acids with a molecular weight of about $39 \mathrm{kDa}$ [5]. Like $\mathrm{LPA}_{4}$, it belongs to the P2Y receptor family. The ligand-binding pattern of $\mathrm{LPA}_{6}$ is quite different from that of $\mathrm{LPA}_{1}$, and the ligand binding pocket of $\mathrm{LPA}_{6}$ is transverse to the membrane opening, and the acyl chain of the lipid used for crystallization is incorporated therein [46]. LPAR6 binds to Gai and Ga12/13 and activates downstream pathways for multiple functions. Activation of the Ga12/13 family induces expression of SRE regulatory genes by activating Rho and ROCK [47]. LPA 6 -mediated Rho-dependent morphological changes and cAMP accumulation were detected by using chimeric Ga13 protein [48]. LPA 6 mostly binds to 2-acyl-LPA instead of l-acyl-LPA. When the promiscuous Ga protein is co-expressed with $\mathrm{LPA}_{6}$, LPA activates $\mathrm{LPA}_{6}$ to increase intracellular $\mathrm{Ca}^{2+}$ and reduce cAMP and ERK1/2 activation which stimulated by forskolin [9, 47]. As already mentioned, the transcriptional regulators YAP and TAZ can be activated by the LPA-LPA $4 / \mathrm{LPA}_{6}-\mathrm{Ga}_{12} / \mathrm{Ga13}$ signaling pathway, and both YAP and TAZ are involved in tumor progression [35]. Moreover, another article mentions the binding of LPA to the LPA6 receptor to regulate vascular permeability [49]. $\mathrm{LPA}_{6}$ also regulates the formation of hair follicles, and the loss of $\mathrm{LPA}_{6}$ leads to congenital alopecia $[46,50]$. Research on the role and mechanism of LPAR6 in different systems is still relatively rare, which may be a future research direction.

\section{The role of LPAR in diseases}

\section{LPAR and cancer}

LPA induces cell proliferation, migration and survival. LPA affects cell morphology, mobility, chemotaxis and invasiveness by stimulating cell cycle, increasing cell viability, and promoting the production of interleukin (IL)-6, IL-8 and vascular endothelial growth factor (VEGF), interleukin (IL)-6, and IL-8. There is a lot of evidence that LPA plays an indispensable part in the occurrence and development of cancer because of its functions [5,51,52]. The purpose of LPA in cancer is mainly achieved through 
its $G$ protein coupled receptor. EDG receptors $\left(\mathrm{LPA}_{1-3}\right)$ play a significant character in various cancers, but the character of non-EDG receptors $\left(\mathrm{LPA}_{4}, \mathrm{LPA}_{5}, \mathrm{LPA}_{6}\right)$ in cancer is currently less studied. Different receptors of LPA receptors play different roles in various tumors to push the proliferation, migration, and antiapoptosis of tumor cells and play a role in preventing the advancement of tumors (Figure 2).

\section{LPAR and ovarian cancer}

A large amount of LPA is present in the ascites of ovarian cancer. Overexpression of $\mathrm{LPA}_{2}$ and $\mathrm{LPA}_{3}$ in ovarian cancer cells stimulate proliferation and migration of ovarian cancer cells [53]. The level of LPAR1 protein was significantly higher in lymph node metastasis and relapsed more in OSC tissues than in primary tumor lesions, and high levels of LPAR1 protein suggested poor prognosis [54]. The $\mathrm{LPA}_{2}$ receptor induces the expression of VEGF by participating in the production of IL8 and induces the expression of cyclin D1 through transcriptional activation, thereby stimulating the growth of ovarian cancer and enhancing the invasiveness of ovarian cancer $[51,52,55,56]$. The study also found that LPA stimulated COX-2 expression and cell movement through the $\mathrm{LPA}_{2}$-Gai-Src-epidermal growth factor receptor (EGFR)-ERK signaling cascade in ovarian cancer cells [57]. The expression of $\mathrm{LPA}_{3}$ receptor is mainly related to malignant cells. $\mathrm{LPA}_{3}$ selectively increases in ovarian cancer cells, and LPA with unsaturated fatty acyl chains is preferred in sn-LPA (common in ascites of ovarian cancer) [56]. Yu et al. reported that the tumor volume and invasiveness of mice injected with SKOV-3 cells expressing LPA receptors increased, and the concentrations of IL-6, IL-8 and VEGF in mouse ascites and serum increased significantly. And tumor volume and invasiveness of $\mathrm{LPA}_{2}$ and $\mathrm{LPA}_{3}$ were significantly increased. HIF-1a is closely related to the occurrence and development of tumors [56]. Ha et al. found that the LPA-LPAR-Gai2 axis can induce pseudo hypoxic response through the Rac-NOXROS-HIF1a pathway, which ultimately leaded to metabolic reprogramming of ovarian cancer cells. This conclusion was verified by establishing two independent mouse models of ovarian cancer cell line xenograft (CDX) [58]. PI3K/Akt pathway is critical in the process of ovarian cancer. LPAR1 plays a paramount role in the invasion, proliferation, migration, and development of ovarian serous cystadenocarcinoma (OSC) intratumoral heterogeneity (ITH) by regulating the activity of PI3K/AKT signaling pathway [54]. When miR-15b was up-regulated, the proliferation of ovarian cancer cells and their apoptosis and senescence were prohibited by the LPAR3-PI3K/Akt pathway [59].

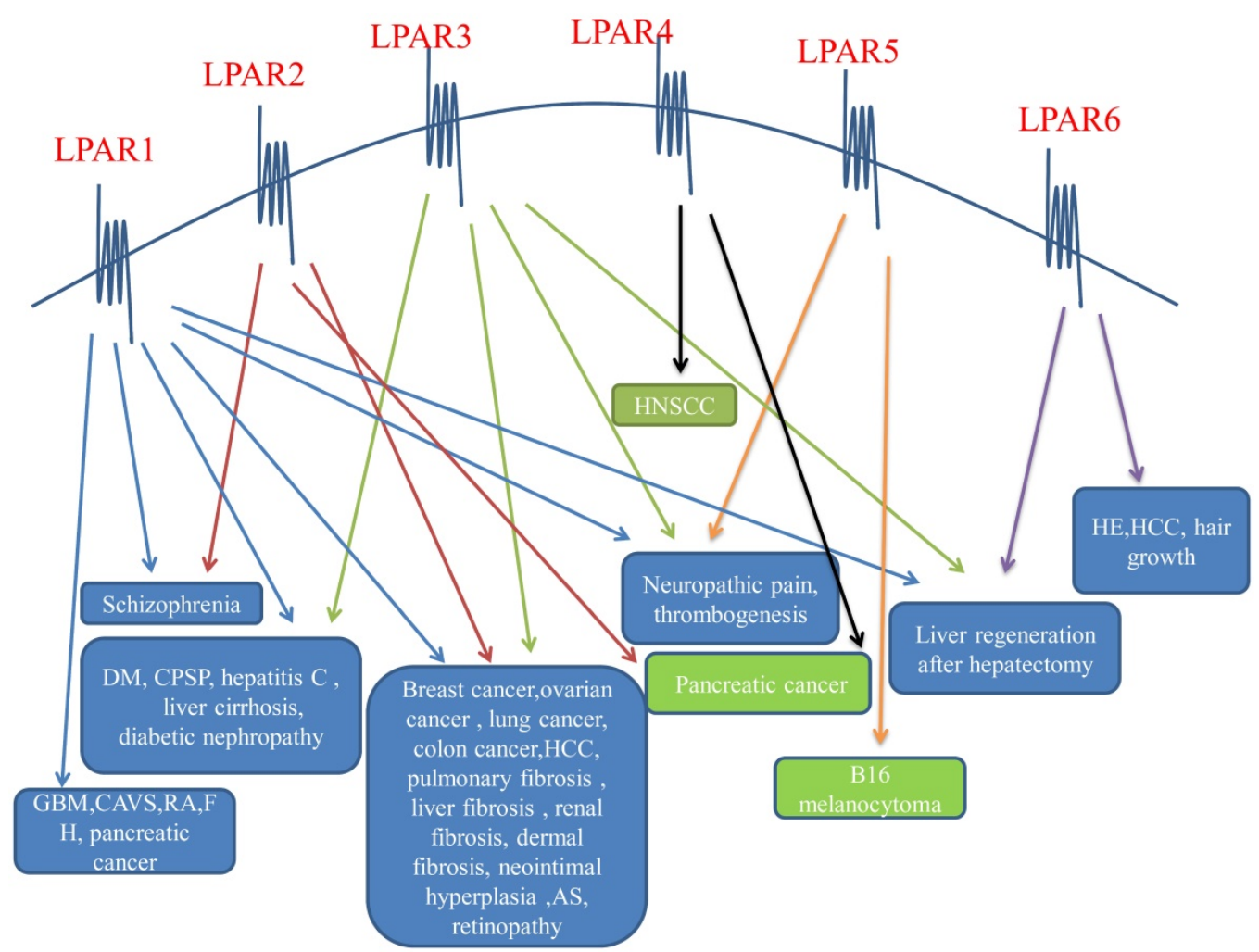

Figure 2. LPA receptors on the cell surface and their effects on diseases. The six LPA receptors have different effects on diseases of different systems, and both promote and inhibit the disease. The blue text box in the above figure indicates that the LPA receptors promotes it, and the green text box indicates that the LPA receptors inhibits it. LPAR: lysophosphatidic acid receptor; DM: diabetes mellitus; CPSP: central post-stroke pain; GBM: glioblastoma multiforme; CAVS: calcified aortic stenosis; RA: rheumatoid arthritis; FH: fetal hydrocephalus; HCC: hepatocellular carcinoma; AS: atherosclerosis; HNSCC: headneck squamous cell carcinoma; HE: hepatic encephalopathy. 
Table 1. The role of LPAR in diseases

\begin{tabular}{|c|c|c|c|c|}
\hline LPAR & Disease & Impact & Mechanism & Reference \\
\hline \multirow{13}{*}{ LPAR1 } & Ovarian cancer & Aggravate & PI3K/AKT pathway $\uparrow$ & Cui et al.,2019 \\
\hline & Glioblastoma & Aggravate & $\mathrm{PKCa} \uparrow$ & Valdés-Rives et al.,2019 \\
\hline & Lung cancer & Aggravate & P53 $\downarrow$ & Murph et al.,2007 \\
\hline & Neuropathic pain & Aggravate & Rho-ROCK pathway $\uparrow, \mathrm{PKC}_{\gamma} \uparrow, \mathrm{Caa} 2 \delta 1 \uparrow$ & Inoue et al.,2004 \\
\hline & Neuropathic pain & Aggravate & macrophages/microglia $\uparrow$ & Velasco et al.,2017 \\
\hline & Atherosclerosis & Aggravate & CXCL12 X, HIF-1a $\uparrow$, SPC $\uparrow$ & Subramanian et al.,2010 \\
\hline & Calcified aortic stenosis & Aggravate & RhoA-NF-kB pathway $\uparrow$ & Nsaibia et al.,2017 \\
\hline & Renal fibrosis & Aggravate & $\begin{array}{l}\text { the myocardin-related transcription factor-serum response factor } \\
\text { pathway } \uparrow, \text { CTGF } \uparrow\end{array}$ & Sakai et al.,2017 \\
\hline & Pulmonary fibrosis & Aggravate & BMSC to differentiate into myofibroblasts $\uparrow, \mathrm{ECM} \uparrow$ & Tang et al.,2014 \\
\hline & Liver fibrosis & Aggravate & a-SMA $\uparrow$, CTGF $\uparrow$, TGF- $\beta 1 \uparrow$ & Eraky et al.,2018 \\
\hline & Diabetic nephropathy & Aggravate & GSK3b (Ser9) phosphorylation $\uparrow$, SREBP1 $\uparrow$, TGF- $\beta \uparrow$ & Li et al.,2017 \\
\hline & Diabetic nephropathy & Aggravate & TLR4 /NF-kB pathway $\uparrow$, NADPH $\uparrow$ & Lee et al.,2019 \\
\hline & Rheumatoid arthritis & Aggravate & RA FLS $\uparrow$ & Miyabe et al.,2014 \\
\hline \multirow{9}{*}{ LPAR2 } & Ovarian cancer & Aggravate & Gai-Src-EGFR-ERK pathway $\uparrow$ & Jeong et al.,2008 \\
\hline & Colon cancer & Aggravate & $\mathrm{cPKC} \uparrow, \beta$-catenin $\uparrow$ & Yang et al.,2005 \\
\hline & Colon cancer & Attenuate & MAGI-3 $\uparrow$ & Lee et al.,2011 \\
\hline & Colon cancer & Aggravate & NHERF-2 $\uparrow$ & Lee et al.,2011 \\
\hline & Pancreatic cancer & Attenuate & Ga12/13-Rho pathway $\uparrow$ & Komachi et al.,2009 \\
\hline & Lung cancer & Aggravate & P53 $\downarrow$ & Murph et al.,2007 \\
\hline & Atherosclerosis & Aggravate & CXCL12 $\uparrow, H I F-1 a \uparrow, S P C \uparrow$ & Subramanian et al.,2010 \\
\hline & Renal fibrosis & Aggravate & Gaq-Rho/ROCK pathway $\uparrow$, TGF- $\beta \uparrow$ & Geng et al.,2012 \\
\hline & Pulmonary fibrosis & Aggravate & TGF- $\beta 1 \uparrow$ & Huang et al.,2013 \\
\hline \multirow{7}{*}{ LPAR3 } & Ovarian cancer & Attenuate & PI3K/Akt pathway $\uparrow$ & Li et al.,2019 \\
\hline & Colon cancer & Aggravate & $\mathrm{cPKC} \uparrow, \beta$-catenin $\uparrow$ & Yang et al.,2005 \\
\hline & Liver cancer & Aggravate & Gai-ERK-MAPK pathway $\uparrow$ & Zuckerman et al.,2016 \\
\hline & Lung cancer & Aggravate & P53 $\downarrow$ & Murph et al.,2007 \\
\hline & Neuropathic pain & Aggravate & macrophages/microglia $\uparrow$ & Velasco et al.,2017 \\
\hline & Atherosclerosis & Aggravate & CXCL12 $\uparrow$, HIF-1a $\uparrow$, SPC $\uparrow$ & Subramanian et al.,2010 \\
\hline & Cardiac fibrosis & Attenuate & $\mathrm{a}-\mathrm{SMA} \uparrow, \mathrm{CTGF} \uparrow, \mathrm{TGF}-\beta 1 \uparrow$ & Eraky et al.,2018 \\
\hline LPAR4 & - & - & - & - \\
\hline \multirow[t]{2}{*}{ LPAR5 } & Melanoma & Attenuate & cAMP $\downarrow$ & Jongsma et al.,2011 \\
\hline & Neuropathic pain & Aggravate & PKD $\uparrow$, microglia $\uparrow$ & Velasco et al.,2017; Plastira et al.,2017 \\
\hline \multirow[t]{2}{*}{ LPAR6 } & Liver cancer & Aggravate & pim-3 $\uparrow$ & Mazzocca et al.,2015 \\
\hline & Hepatic encephalopathy & Aggravate & Ga12/13-Rho pathway $\uparrow$, BBB $\uparrow$ & Herr et al.,2019; Masago et al.,2018 \\
\hline \multirow[t]{2}{*}{ LPAR } & Ovarian cancer & Aggravate & Rac-NOXROS-HIF1a pathway $\uparrow$ & Ha et al.,2018 \\
\hline & Alzheimer's disease & Aggravate & $\begin{array}{c}\mathrm{A} \beta \text { accumulation } \uparrow \text {, tau hyperphosphorylation } \uparrow, \text {, neuronal } \\
\text { dysfunction } \uparrow\end{array}$ & Ramesh et al.,2018 \\
\hline $\begin{array}{l}\text { PKCa: } p \\
\text { muscle } p \\
\text { element } \\
\text { regulate }\end{array}$ & $\begin{array}{l}\text { kinase Ca; PKCY: protein } \\
\text { iitor cells; CTGF: connecti } \\
\text { ng proteins } 1 \text {; TGF- } \beta 1 \text { : tra } \\
\text { ein kinases; } c \text { PKC: classic } \\
\text {; cAMP: cyclic adenosine }\end{array}$ & $\begin{array}{l}\text { se } C \gamma \text {; LPAR: } \\
\text { sue growth } \mathrm{f} \\
\text { ming growth } \\
\text { tein kinase } \mathrm{C} \\
\text { phosphate; I }\end{array}$ & $\begin{array}{l}\text { hosphatidic acid receptors; CXCL12: CXC motif ligand } 12 \text {; HIF-1c } \\
\text { BMSC: bone marrow-derived mesenchymal stem cells; ECM: ext } \\
\text { B1; NADPH: nicotinamide adenine dinucleotide phosphate; RA: } \\
\text { SI-3: inverted orientation-3; NHERF-2: } \mathrm{Na}^{+} / \mathrm{H}^{+} \text {exchange regulat } \\
\text { rotein kinase D; BBB: blood-brain barrier. }\end{array}$ & $\begin{array}{l}\text { poxia-inducible factor-1a; SPC: smooth } \\
\text { llular matrix; SREBP1: sterol-regulatory } \\
\text { umatoid arthritis; ERK: extracellular } \\
\text { factor-2; MAPK: mitogen-activated }\end{array}$ \\
\hline
\end{tabular}

\section{LPAR and breast cancer}

In breast cancer (BC), the autotaxin (ATX)-LPA axis promotes $\mathrm{BC}$ cell invasion, proliferation and antiapoptosis through high ATX expression and binding to $\mathrm{LPA}_{1-3}$, thereby brings about mammary gland inflammation and tumor formation. This is related to with activation of the LPA receptors by the ATX-LPA axis, resulting in downstream pathways PI3K/Akt, p38-PI3K and ERK/MAPK, wnt/ $\beta$-catenin, estrogen receptor (ER), and cytokine activation [60]. The metastasis of cancer cells mainly involves $\mathrm{LPA}_{1}$ receptors. Debio-0719 (LPA ${ }_{1}$ receptor inhibitor) can prohibit the metastasis of cancer cells to the lung and liver in 4T1 mouse breast cancer model, and Debio0719 can also hinder the metastasis of cancer cells to the lung in MDA-MB-231T human breast cancer model. $\mathrm{LPA}_{1}$ siRNA does not alter primary tumor size, but also inhibits cancer cell metastasis [61]. LPA receptor can also promote xenograft bone metastasis of breast cancer [62]. All these indicate that metastasis of breast cancer is closely linked to $\mathrm{LPA}_{1}$ receptor. In the previous discussion of ovarian cancer, we mentioned that the effect of LPAR on the transcription factor hypoxia-inducible factor-1a (HIF-1 $\alpha$ ) is a factor in the development of ovarian cancer. $\mathrm{Li}$ et al. examined the tissue samples of $156 \mathrm{BC}$ patients and found that the expression of $\mathrm{LPA}_{2}$ in $\mathrm{BC}$ tissues was 
higher than that in adjacent tissues, and the expression of $\mathrm{LPA}_{2}$ was more in postmenopausal women. This indicates that the overexpression of $\mathrm{LPA}_{2}$ is closely related to the canceration of postmenopausal $\mathrm{BC}$. In vitro experiments have also shown that $\mathrm{LPA}_{2}$ is positively correlated with HIF-1a expression, and can also promote the proliferation, migration and invasion of BC cells [63]. Liu et al. found that transgenic mice overexpressing ATX and LPAR1-3 had an increased risk of breast cancer, and LPAR3 transgenic mice had the highest metastasis rate [62]. Popnikolov and others confirmed that 87 patients with invasive human breast cancer were more prone to lymph node metastasis by immunohistochemical analysis. This suggests that LPA mediates tumor aggressiveness primarily through the $\mathrm{LPA}_{3}$ receptor [64]. In addition, $\mathrm{LPA}_{3}$ can contribute to the growth of triple-negative breast cancer cell lines and is of great significance for the early diagnosis of triple-negative breast cancer $[65,66]$. Tao et al. tested 98 clinical BC and adjacent tissues and found that the expression of LPAR6 in BC was much lower than that in adjacent tissues, and the results were consistent with those obtained from the database. Knockdown of LPAR6 in cell experiments enhanced tumor cell proliferation and invasion. It is suggested that LPAR6 may play a role in inhibiting tumor development in BC [67].

\section{LPAR and colon cancer}

In colon cancer, LPA makes human colon cancer cell DLD1 more susceptible to metastasis by binding to $\mathrm{LPA}_{1}$. LPA enhances colon cancer cell proliferation and angiogenesis factor production via $\mathrm{LPA}_{2}$ [68]. Earlier studies found that $\mathrm{LPA}_{2}$ receptors were important receptors for LPA in the colon and mediated mitogenic signals in human colon cancer cells [69]. Lin et al. found that in $\mathrm{LPA}_{2}-/$ mice, mucosal damage in the colon was reduced and tumor growth was suppressed [70]. $\mathrm{LPA}_{2}$ and $\mathrm{LPA}_{3}$ are targets of LPA-induced proliferation of HCT116 and LS174T colon cancer cells by specific RNA interference (RNAi), and $\mathrm{LPA}_{2}$ and $\mathrm{LPA}_{3}$ promote the proliferation of colon cancer cells through classical protein kinase $C$ (cPKC)-mediated activation of the $\beta$-catenin pathway [71]. $\mathrm{LPA}_{2}$ receptor signaling regulates the function of colon cancer cells and is also associated with membrane-associated guanylate kinases, including MAGI-3 and NHERF-2. NHERF-2 competes with MAGI-3 for binding to $\mathrm{LPA}_{2}$, which has the opposite effect on the function of the $\mathrm{LPA}_{2}$ receptor to regulate colon cancer cells. The migration and invasion of colon cancer cells was inhibited when $\mathrm{LPA}_{2}$ binds to MAGI-3, and the opposite effect to NHERF-2 [17]. Beyond that, it was found that $\mathrm{LPA}_{4}$ and $\mathrm{LPA}_{6}$ can inhibit the locomotor activity of colon cancer cells [33].

\section{LPAR and liver cancer}

If factors such as hepatitis are not removed in time, the liver will continue to be damaged, and fibrosis will intensify, which may develop into cirrhosis and liver cancer. Hepatocellular carcinoma (HCC) is a type of primary hepatic carcinoma, accounting for $90 \%$ of primary liver cancer. In HCC tissues, LPA expression was higher and LPA receptors were also highly expressed. In liver cancer, studies have found that the expression of ATX and $\mathrm{LPA}_{1}$ receptors in $\mathrm{HCC}$ was higher than that in normal tissues. $\mathrm{LPA}_{1}$ receptor inhibition and inhibition of phosphoinositide 3-kinase (PI3K)/Akt and protein kinase $\mathrm{Cd}(\mathrm{PKCd}) / \mathrm{p} 38-\mathrm{MAPK}$ pathways all result in decreased MMP-9 activity and invasiveness of HCC. This demonstrates that LPA enhances MMP-9 expression and HCC invasion through $\mathrm{LPA}_{1}$ receptor and synergistic activation of the PI3K and p38MPAK signaling cascades $[4,72,73]$. The migration ability of SKHep1 cells can be enhanced by LPA $_{3}$-Gai-ERK-MAPK signaling pathway, indicating that LPAR3 can promote the development of liver cancer [74]. Okabe et al. also suggested that LPAR3 was related to the migration of liver cancer cells [75]. Mazzocca et al. confirmed in vitro experiments that LPAR6 promoted the proliferation and tumorigenic phenotype of HCC cells, and established a relevant model to prove that LPAR6 promotes tumor growth, and the higher the expression level of LPAR6 in tumor tissues of liver cancer patients, the worse the prognosis of patients. Abnormally expressed LPAR6 can activate the protooncogene pim-3 via the signal transducers and activators of transcription 3 (STAT3) binding site, thereby maintaining the tumor proliferative capacity and tumorigenic capacity of HCC [76]. LPAR1/3/6 mRNA expression was more elevated than non-tumor liver tissue, and $\mathrm{LPA}_{6}$ mRNA expression was highest. Regarding the role of LPA and its receptors in hepatocellular carcinoma, the researchers suggest that on the one hand, LPA produced by other pathways promotes the development of HCC. On the other hand, HCC produces LPA and can continue to promote HCC progress in combination with LPAR. For example, the growth and progression of HCC are maintained along with the autocrine loop produced by LPAR6 in tumor cells $[77,78]$. These results indicate that the function of LPA and its receptors in the development of HCC cannot be ignored. In addition, Enooku et al. analyzed liver cancer tissues and adjacent tissues of 58 patients with HCC and found that the high expression of LPAR2 and LPAR6 often indicated that the tumor has a higher degree of 
malignancy [79].

\section{LPAR and pancreatic cancer}

In pancreatic cancer, the progress of PANC-1 cells can be promoted by $\mathrm{LPA}_{1}$ and $\mathrm{LPA}_{3}$, suggesting that LPAR1 and LPAR3 contribute to the movement and development of pancreatic cancer cells [80], while LPA actively inhibits the action of pancreatic cancer cells through LPAR2-Ga12/13-Rho signal transduction pathway [81]. Several other studies have also shown that LPAR1 can promote the metastasis and invasion of pancreatic cancer cells, while LPAR2 has the opposite effect [81,82]. Komachi et al. used oral administration of Ki16198 (specific inhibitors of LPAR1 and LPAR3) in nude mice modeled with pancreatic cancer cells, which inhibited tumor growth and reduced invasion and metastasis of other organs [83]. Yang et al. proposed that YAP promoted the migration and invasion of pancreatic cancer cells by up-regulating LPAR3 in cells [84]. Furthermore, by using shRNA to establish knockdown models-PANCsh4, PANC-sh5, PNAC-sh6, $\mathrm{LPA}_{4}$ was found to inhibit the development of lung cancer, while $\mathrm{LPA}_{5-6}$ promoted pancreatic cancer [65].

\section{LPAR and glioblastoma}

Glioblastoma (GBM) is one of the most aggressive brain tumors. Earlier research discovered that $\mathrm{LPA}_{1}$ was highly expressed in the brain and participated in various activities of the nervous system [5]. Recently, $\mathrm{LPA}_{1}$ receptor was discovered related to the proliferation and migration of GBM. In three GBM cell lines, LPA induces PKCa activation by $\mathrm{LPA}_{1}$, leading to nuclear translocation of kinases, increasing cell number and increasing cell viability $[85,86]$.

\section{LPAR and melanoma}

LPAR1, LPAR2 and LPAR5 play essential roles in the invasion and metastasis of melanoma. Host $\mathrm{LPA}_{1}$ and $\mathrm{LPA}_{5}$ receptors promote $\mathrm{B} 16 \mathrm{~F} 10$ melanoma cell-derived lung metastasis. The expression of $\mathrm{LPA}_{2}$ in tumor cells promotes invasion, but $\mathrm{LPA}_{5}$ inhibits invasion. Jongsma et al. also proposed that $\mathrm{LPA}_{5}$ receptors inhibited melanoma cell migration and were related to downstream cAMP [87]. It was worth noting that $\mathrm{LPA}_{5}$ receptor on cytotoxic $\mathrm{CD} 8{ }^{+} \mathrm{T}$ cells acts contrary to $\mathrm{LPA}_{5}$ receptor in tumor cells. Its activation inhibits the activation and proliferation of $\mathrm{T}$ cells, thus facilitating the escape of host immunity [72]. In another study, by using LPAR1/3 antagonists, it was suggested that LPAR3 was related to the activity of B16F10 metastatic melanoma cells and may be an important target for the treatment of melanoma [88].

\section{LPAR and lung cancer}

In A549 lung tumor cells, LPA inhibits P53 activity via $\mathrm{LPA}_{1-3}$ receptor, reduces p53-dependent transcription, promotes loss of p53 protein, and protects tumor cells from actinomycin D-induced apoptosis [89]. It is suggested that the expression of $\mathrm{LPA}_{1-3}$ receptor contributes to the development of lung cancer. However, it was found that increased migration of rat lung tumor cells may be related to the loss of LPAR3 [90]. Yamada et al. proposed that mutations in the LPAR1 gene promoted the development of rat lung adenomas into lung adenocarcinomas [91]. Magkrioti et al. also proposed that gene deletions of LPAR1 and nucleotide pyrophosphatase/phosphodiesterase 2 (ENPP2) slowed the progression of lung fibrosis and lung cancer [92].

In the above discussion, we can see that EDG receptors are immeasurable in the progress of cancer, and the role of the same LPA receptor in different cellular environments was not the same. Future research can focus on the study of anticancer drugs based on LPA receptors.

\section{LPAR and nervous system disease}

Lysophosphatidic acid (LPA) is essential for brain development and nervous system function, signaling through six different G-protein coupled receptors (LPAR1-6). The role of LPA receptors in the nervous system is one of the earliest research findings. The $\mathrm{LPA}_{1}$ receptor was first discovered in the $\mathrm{VZ}$, and the $\mathrm{LPA}_{1}$ receptor was most widely distributed in the nervous system [8].

\section{LPAR and neuropathic pain}

Through pharmacological and genetic studies, it was found that in mice lacking the $\mathrm{LPA}_{1}$ receptor, due to the inability to activate the Rho-ROCK pathway, abnormal mechanical pain, thermal hyperalgesia and demyelination, up-regulation of PKCY and Caa281 expression was inhibited, and the same phenomenon occurred after intrathecal injection of BoTXC3 into peripheral nerves [93]. In a novel CPSP model developed by photochemically induced thrombosis (PIT) and tissue plasminogen activator, $\mathrm{LPA}_{1 / 3}$ antagonist Ki-16425 treatment can reverse established heat or mechanical hyperalgesia, blocking established CPSP. This also indicates that LPAR1 and LPAR3 are involved in neuropathic pain [24]. Microglia are involved in the physiological and pathological processes of the nervous system and are permanent immune cells in the central nervous system (CNS). LPA may activate macrophages/microglia via LPAR1 and LPAR3 and promote self-amplification of LPA, increasing microglial migration and pro- 
inflammatory phenotype through the LPAR5/protein kinase D (PKD) axis. Activation and migration of microglia are associated with demyelination in the spinal cord after injury, and microglia are more involved in the initiation of neuropathic pain (NP) [94, 95]. In the cuprizone (CPZ)-induced multiple sclerosis (MS) model, $\mathrm{LPA}_{5}$ signaling mediates pain allergy induced by A-delta fibers and demyelination produced by CPZ. At the same time, phosphorylation of cAMP response element binding protein may lead to $\mathrm{LPA}_{5}$-mediated hyperalgesia in peripheral nerve injury in mice. This indicates that $\mathrm{LPA}_{5}$ signaling is related to neuropathic pain mediated by multiple sclerosis [96]. It was found that intravenous LPA and GGPP (LPA ${ }_{5}$ agonists) induced allodynia, but GGPP-induced allodynia did not show up in $\mathrm{LPA}_{5}-\mathrm{KO}$ mice, indicating pain signals in the spinal cord by $\mathrm{LPA}_{5}$ transfer [94-96].

\section{LPAR and fetal hydrocephalus}

There is a common neurological disease in the newborn, fetal hydrocephalus (FH), and its occurrence is closely related to LPA and its receptors. In a mouse model of intracranial hemorrhage, by exposing the mouse embryonic brain to blood or LPA, the $\mathrm{LPA}_{1}$ receptor, which is dependent on the expression of neural progenitor cells (NPC), is overactivated, resulting in disruption and thinning of the cortical layer, ultimately leading to FH. FH was also found to be staged, suggesting that LPA receptors modulators can be used in the short-term to improve hydrocephalus without affecting LPA-mediated normal cortical development [97]. Park et al. demonstrated that LPA may be involved in the development of fetal hydrocephalus by regulating the expression of the downstream factor Yap [98]. When LPA was used to induce the production of posthemorrhagic hydrocephalus $(\mathrm{PHH})$ by LPAR1-5 single gene knockout mice, LPAR1 and LPAR3 were found to be the main receptors of LPA-induced PHH production. When Ki16425 (LPAR1/3 inhibitor) was used in mice without gene knockout, the probability and severity of $\mathrm{PHH}$ production were reduced. This indicates that LPAR1 and LPAR3 may be key receptors for fetal hydrocephalus [99].

\section{LPAR and hepatic encephalopathy}

In hepatic encephalopathy mice, elevated serum ATX activates the LPA6-associated Ga12/13-Rho pathway in cerebral capillary vessel endothelial cells, resulting in enhanced blood-brain barrier (BBB) permeability and brain edema. The role of the LPA6 receptor in hepatic encephalopathy is suggested [100, 101]. In addition, LPA and the tricyclic antidepressant amitriptyline (TCA) signaled LPAR1 to cut down
P-glycoprotein transport in the $\mathrm{BBB}$, thereby increasing drug delivery in blood-brain therapy [102].

\section{LPAR and Alzheimer's disease}

Alzheimer's disease (AD) is a chronic neurodegenerative disease distinguished by cognitive deterioration and behavioral abnormalities. LPA receptor-mediated $A \beta$ accumulation, tau hyperphosphorylation and neuronal dysfunction are associated with AD. At the same time, traumatic brain injury, metabolic syndrome and chronic hypoperfusion are all mediated by LPA receptors and can be further developed into AD [103].

\section{LPAR and retinopathy}

The retina was an extension of the nervous system, and studies have shown that LPA was associated with retinopathy. In adult rats, the expression of LPA1 and LPA2 in retinal ganglion cells increased significantly after retinal ischemia, and LPA1 mediated retinal ganglion cell death in retinopathy of premature infants. In contrast, LPAR13 expressed by retinal pigment epithelial cells can promote retinal healing. It suggests that LPA has neuroprotective effects on the retina by binding to different LPA receptors on different cells, or has a neurodegenerative effect [104]. LPAR1 and LPAR2 were also associated with schizophrenia $[100,104]$.

In summary, considering the role of LPA in the nervous system, we can develop corresponding drugs to treat nervous system diseases by studying the mechanism of LPA and its receptors in the nervous system.

\section{LPAR and cardiovascular system disease}

With lifestyle changes and an aging population, cardiovascular disease (CVD) has become a major threat to the health. In China, the prevalence of CVD is high, with about 290 million people affected by CVD, and the number is still growing [105]. LPA and its receptors are critical for the development of cardiovascular disease. First, as mentioned earlier, the LPA4 signaling pathway in the vascular endothelium was essential for vascular development. Furthermore, the process of atherosclerosis and thrombosis was also associated with LPA and its receptors [34].

\section{LPAR and atherosclerosis}

When blood vessels are damaged, phenotypic regulation of vascular smooth muscle cells (SMCs) (including dedifferentiation, proliferation, and migration) and CXC motif ligand 12 (CXCL12)dependent SPCs mobilization, as well as promotion of intimal hyperplasia, occur. These are the critical causes of atherosclerosis and stenosis. The ability of $\mathrm{LPA}_{1}$ and $\mathrm{LPA}_{2}$-deficient mouse vascular SMC to 
migrate is reduced, and the intimal hyperplasia caused by vascular injury is reduced, but only $\mathrm{LPA}_{1}$-deficient mice may have an effect of enhancing vascular injury. This may be related to the increased migration of vascular smooth muscle cells caused by concurrent LPAR3 compensatory upregulation. It was worth noting that although LPA was associated with blood pressure regulation, it was not associated with LPAR1 and LPAR2 [106]. The use of Ki16425 (LPA 1 and $\mathrm{LPA}_{3}$ antagonists) after vascular injury significantly reduced neointimal expression of CXCL12 and hypoxia-inducible factor (HIF)-1a, mobilization of CXCL12-dependent SPCs, and also inhibited neointimal hyperplasia. These indicate that $\mathrm{LPA}_{1}, \mathrm{LPA}_{2}$ and $\mathrm{LPA}_{3}$ mediate the formation of neointimal after vascular injury [14]. In addition, the long-term use of Ki16425 can also inhibit the recruitment of monocytes that can lead to atherosclerosis. Studies have shown that LPA promotes the adhesion of monocytes induced by CXCL1 through the release of endothelial cell CXCL1 mediated by $\mathrm{LPA}_{1}$ and $\mathrm{LPA}_{3}$ receptors [107]. The occurrence of atherosclerosis was also associated with inflammation. In recent studies, it was found that in LDLr-/-mice, Ki16425 induced a systemic antiinflammatory response by inhibiting CCL2-CCR2 signaling. This enhanced the anti-inflammatory innate and adaptive immune response and lowered plasma cholesterol levels, ultimately damaging the progression of atherosclerosis [108]. In summary, $\mathrm{LPA}_{1-3}$ was a critical aim for the cure of atherosclerosis and neointimal formation after stent implantation.

\section{LPAR and thrombogenesis}

Thrombogenesis is another risk factor for cardiovascular disease. In one aspect, LPA mediates platelet activation by stimulating LPAR1 and LPAR3, and LPA was a crucial thrombogenic component of the plaque lipid core. Selective antagonists of LPAR1 and LPAR3 dioctylphosphatidic acid [PA (8:0)] and dioctylglycerol pyrophosphate [DGPP (8:0)] can selectively suppress induction by LPA and mox-LDL Changes in platelet shape (inhibition of platelet activation by LPA), thereby reducing the formation of intravascular thrombus [109]. On the other hand, plaque rupture caused by the further development of atherosclerotic plaques can lead to acute thrombotic occlusion of the arterial lumen, and there was a risk of cardiovascular diseases such as myocardial infarction and stroke. Studies have shown that after rupture of atherosclerotic plaques, LPA exposed from lipid nucleus induces platelet shape changes by binding to $\mathrm{LPA}_{5}$ and synergizes with adenosine diphosphate (ADP) to stimulate platelet aggregation and thrombosis [110]. In another study on thrombosis, it was also suggested that LPA can enhance the assembly of fibrin and thus promote thrombosis [111].

\section{LPAR and calcified aortic stenosis}

Calcified aortic stenosis (CAVS) is also one of the common chronic CVD, and its main feature is progressive mineralization of the aortic valve. The research discovered that Ki1642 was given to the IGFII mouse high-fat and high-sucrose (HF-HS) diet for 6 months, and the rate of progression of aortic stenosis was reduced by a factor of three. Since LPAR3 was not expressed in VICs, LPAR1 was suggested to encourage the progress of aortic stenosis. Moreover, studies have shown that the mechanism may be that oxidative transformation of low-density lipoprotein (OxLDL)-LPA promotes the mineralization and osteogenic transformation of VIC by activating the LPAR1-RhoA-NF-kB pathway, thereby improving the development of CAVS [112].

In summary, LPA receptors (especially LPAR1 and LPAR3) play a vital part in the treatment of CVD. LPAR1 and LPAR3 can be used as the next target for the study of cardiovascular drugs.

\section{LPAR and Fibrosis}

Fibrosis is closely associated with end-stage organ failure, leading to severe morbidity and mortality [113]. Here we describe the role of LPA and its receptors in the fibrosis progression in order to provide direction for the treatment of disease.

\section{LPAR and renal fibrosis}

LPA promotes the advancement of renal fibrosis through the $\mathrm{LPA}_{1}$ receptor. In the mice with renal interstitial fibrosis (TIF) induced by unilateral ureteral obstruction (UUO), the concentration of ATX and LPA were increased, and real-time reverse transcription polymerase chain reaction (RT-PCR) showed that $L^{2} A_{1}$ receptor was significantly up-regulated and $\mathrm{LPA}_{3}$ receptor was significantly down regulated [114]. Fibroblast migration and proliferation can be stimulated by ATX-LPA-LPA 1 receptor signaling [115]. The study also found that renal fibrosis was significantly attenuated in $\mathrm{LPA}_{1}-$-mice and mice treated with Ki16425. Moreover, when the $\mathrm{LPA}_{1}$ receptor was blocked, profibrotic cytokines (connective tissue growth factor and transforming growth factor- $\beta$ ) are significantly down-regulated [114]. In one study, it was confirmed that LPA-LPA 1 signaling directly induces connective tissue growth factor (CTGF) expression in primary proximal tubular epithelial cells via the myocardin-related transcription factor-serum response factor pathway [116]. It was worth noting that the glomerular $\mathrm{LPA}_{1}$ receptor does not participate in the role of TIF caused by UUO [114]. Geng et al. 
proposed that after renal ischemia-reperfusion injury, LPA mainly induced TGF- $\beta$ activation through the $\mathrm{LPA}_{2}$-Gaq-Rho / ROCK pathway, thereby promoting the development of renal fibrosis [117]. Besides, increased expression of $\mathrm{LPA}_{1}$ receptor was also detected in TIF induced by a mouse model of nephrotoxic serum (NTS) nephritis, which was more similar to the progression of human kidney disease, and this model is mainly associated with glomerulonephritis [118]. Mirzoyan et al. also found that LPA is involved in subtotal nephrectomy (SNx) -mediated renal fibrosis. However, the specific LPA receptors and mechanisms are unclear [119].

\section{LPAR and pulmonary fibrosis}

Fibroblast accumulation and vascular leakage are principal factors in the pathogenesis of pulmonary fibrosis. In previous studies, LPA levels were remarkably elevated in bronchoalveolar lavage (BAL) fluid collected from patients with idiopathic pulmonary fibrosis (IPF) compared to the normal control group [120,121]. In order to study the effect of LPA and LPA receptors in pulmonary fibrosis, bleomycin was used to attack mice lacking $\mathrm{LPA}_{1}$. It was found that the excessive accumulation of fibroblasts in damaged lungs and the persistent vascular leakage caused by injury were significantly reduced [121,122]. Secondly, AM966, an effective antagonist of $\mathrm{LPA}_{1}$ receptor, was used in bleomycin-induced fibrosis model in mice. It not only dwindled vascular leakage, tissue damage, inflammation, and fibrosis but also dwindled the concentration of several pro-fibrosis and pro-inflammatory cytokines in bronchoalveolar lavage fluid (BALF) [123]. In a randomized, doubleblind, placebo-controlled clinical trial, the use of the $\mathrm{LPA}_{1}$ receptor antagonist BMS-986020 significantly slowed the decline of FVC (forced vital capacity) in patients with IPF, and alleviated clinical symptoms [124]. It can be seen from the above studies, LPA contributes to the progress of pulmonary fibrosis through the $\mathrm{LPA}_{1}$ receptor, especially IPF. In bleomycin-induced pulmonary fibrosis, the progression of fibrosis can also be suppressed by knocking out other LPA receptors. Another study showed that bleomycin-induced lung injury, fibrosis and death can also be alleviated by knocking out the $\mathrm{LPA}_{2}$ receptor. Moreover, these phenomena and knockdown of $\mathrm{LPA}_{2}$ attenuated LPA-induced expression of transforming growth factor $\beta 1$ (TGF- $\beta 1$ ) and differentiation of lung fibroblasts. Hence $\mathrm{LPA}_{2}$ receptor was also important in the process of pulmonary fibrosis [125]. Pulmonary fibrosis is a common and serious complication of radiation therapy for lung cancer. $\mathrm{LPA}_{1} / \mathrm{LPA}_{3}$ inhibitor
VPC12249 can inhibit the expression of fibroblast-promoting cytokines TGF $\beta 1$ and CTGF in vivo, leading to a decrease of fibroblast proliferation and the slow progress of radiation-induced pulmonary fibrosis in mice [126]. Regarding the mechanism of LPA and its receptors promoting pulmonary fibrosis, a study suggested that LPA-LPA 1 pathway could induce bone marrow-derived mesenchymal stem cells (BMSC) to differentiate into myofibroblasts and promote the secretion of extracellular matrix (ECM), thereby promoting pulmonary fibrosis. Moreover, $\mathrm{LPA}_{1}$ antagonist Antalpa1 can inhibit these phenomena. After lung injury, myofibroblasts accumulate and activate, secrete excessive ECM, and eventually form fibrotic foci [127].

\section{LPAR and liver fibrosis}

Inflammation and other hepatic damaging factors activate hepatic stellate cells, make myofibroblasts accumulate and secrete excessive ECM, and then lead to liver fibrosis. The process of fibrosis is also mentioned earlier in this article. Regarding liver damage, studies have shown that when LPA can increase GSH levels, sustained phosphorylation of c-Jun N-terminal kinase (JNK) caused by acetaminophen (APAP) administration is blocked. Furthermore, blocking the production of inflammatory cytokines (TNF- $\alpha$ and IL-1 $\beta$ ) protects against APAP-induced acute liver injury. But this process was independent of LPA receptors [128]. Hepatitis was a key factor in the development of liver fibrosis. Make use of vitro hepatocytes and in vitro liver culture systems, as well as human liver chimeric mice and HCC tissues, the researchers demonstrated that the ATX-LPA signal axis activates PI3K and stabilizes HIF-1 a, which positively regulates hepatitis $\mathrm{C}$ virus (HCV) RNA replication, and this process may be related to LPA1 and LPA3 receptors, promoting disease progression to liver fibrosis and hepatocellular carcinoma [129]. In another study, Silymarin, caffeine and their combinations significantly improved liver fibrosis induced by thioacetamide (TAA) by downregulating LPAR1, and downregulated a-SMA, CTGF and TGF- $\beta 1$, suggesting that LPAR1 may promote the progress of liver fibrosis through a-SMA, CTGF and TGF- $\beta 1$ [130]. This is also consistent with the mechanism of pulmonary fibrosis mentioned above. In addition, hepatitis $C$ virus infection promotes liver fibrosis, and when ATX and LPA signals are suppressed, it reduces hepatitis C virus replication [129]. The expression of serum ATX was also closely related to liver fibrosis, which also suggests that the ATX-LPA axis plays an important role in liver injury [131]. 


\section{LPAR and other fibrosis}

In addition to renal, pulmonary and liver fibrosis, studies have shown that $\mathrm{LPA}_{1}$ receptors can also promote the development of dermal fibrosis in bleomycin-induced skin fibrosis models, and is also related to the expression of TGF- $\beta 1$ and CTGF [132]. In a study on ventricular remodeling, it was found that OGN (osteoglycin) in the heart can bind to LPAR3 and attenuate the activation of EGFR signals through the Ga12/13/Rho/ROCK pathway, thereby inhibiting myocardial fibroblast (CMF) proliferation And migration. This suggests that LPAR3 may have a role in regulating fibrosis of the heart [133]. LPA and its receptors are also involved in adipose tissue fibrosis. Rancoule et al. injected intraperitoneal injection of Ki16425 (LPAR1/LPAR3 antagonist) to $\mathrm{db} / \mathrm{db}$ mice to reduce AT (adipose tissue) fibrosis, and experimentally found that LPAR1 may be the main receptor for LPA-promoting fibrosis [134].

\section{LPAR and diabetes}

\section{LPAR and diabetes}

Diabetes has become a disease that cannot be neglected. The occurrence of diabetes was related to many factors. Here we mainly discuss the effects of LPA and its receptors on diabetes. Current research indicates that LPA and its receptors have different regulatory effects on diabetes and its complications. Studies have shown that LPA boosts glucose uptake by stimulating skeletal muscle and fat cells, thereby reducing blood glucose levels in diabetic mice treated by streptozotocin (STZ). Moreover, the effect of LPA on glucose uptake can be entirely inhibited by Ki16425 (LPA $1 / 3$ receptor antagonist) [135]. LPA also modulated NHE3 through an insulin-independent pathway that improves diarrhea in diabetic patients [136]. From the above studies, it can be seen that LPA and its receptors can effectively balance blood sugar and improve some diabetic complications, but in other studies, they have found their effects to be opposite.

\section{LPAR and diabetic nephropathy}

Diabetic nephropathy is a common complication of diabetes. Its occurrence was related to the angiogenesis and fibrosis promoted by protease, growth factor, cytokines and chemokines released from renal cells $[137,138]$. Studies have found that after using $\mathrm{LPA}_{1 / 3}$ receptor antagonist Ki16425 or BMS002 in $\mathrm{db} / \mathrm{db}$ mice, kidney damage was significantly reduced, and the progression of diabetic nephropathy was slowed down. This phenomenon was associated with a decrease in GSK3b (Ser9) phosphorylation and SREBP1 (sterol-regulatory element binding proteins 1) activation caused by inhibition of LPAR1, and a subsequent diminish in TGF- $\beta$ expression. As mentioned earlier in this paper, LPA can induce TGF- $\beta$ to promote the development of renal fibrosis [137]. Beyond that, it may also be related to the decrease in GFR caused by LPAR inhibition [138,139]. Since Ki16425 and BMS002 are antagonists of the $\mathrm{LPA}_{1}$ receptor and the $\mathrm{LPA}_{3}$ receptor, another study used the LPAR1-specific antagonist AM095 to research the function of the LPAR1 in diabetic nephropathy. The study found that in a mouse model induced by STZ, AM095 inhibited renal cell inflammatory signaling cascade and reduced renal damage by inhibiting the TLR4/NF- $\mathrm{kB}$ and NADPH oxidase systems. The role of $\mathrm{LPA}_{1}$ receptor in the development of diabetic nephropathy was more clearly defined [140].

\section{LPAR and obesity}

As we all known, obesity is one of the risk factors for diabetes. It was found that after six weeks of the LPA1/3 receptor antagonist Ki16425, the fat mass and white fat cell size of HFHS-fed C57B16 mice increased significantly. Moreover, the ATX-LPA axis can cause obesity-induced insulin resistance by impairing PPARY expression and activity. The above content showed that LPA receptors played a crucial part in the development of obesity and diabetes [141]. After LPAR1-KO mice were fed high-fat and low-fat diets, compared with wild-type mice, no significant changes in body weight and fat were observed. It was suggested that LPAR1 may play a key role in lipid uptake [142].

Current studies on the relationship between diabetes and LPA and its receptors are limited to LPA and LPAR1 and LPAR3. It is still unclear whether other LPA receptors affect the development of diabetes and its complications. Future studies can focus on related drug studies and other receptor effects targeting LPAR1 and LPAR3.

\section{LPAR and other diseases}

\section{LPAR and rheumatoid arthritis}

Rheumatoid arthritis (RA) is a common chronic inflammatory disease, which is characterized by synovial proliferation, fibroblast-like synoviocytes (FLS) proliferation, angiogenesis, inflammatory cell infiltration and bone destruction of various joints. Miyabe et al. demonstrated that the expression of LPAR1 in the synovium of RA patients was high, and in $\mathrm{LPA}_{1}-$-mice or mice using $\mathrm{LPA}_{1}$ antagonists, inflammatory cell infiltration and joint destruction in bones were reduced. In vitro experiments it was also shown that $\mathrm{LPA}_{1}$ can promote the formation of osteoclasts [143]. In the $\mathrm{K} / \mathrm{BxN}$ serum metastatic arthritis model, after $\mathrm{LPA}_{1 / 3}$ receptor antagonists were 
used, apoptosis increased, inflammatory mediators decreased, and bone remodeling protein decreased. These ultimately weaken the severity of arthritis. It was found that the LPA-LPA 1 signaling pathway promoted the development of rheumatoid arthritis by enhancing the proliferation and migration of RA FLS and the production of inflammatory mediators [144, 145]. Orosa et al. also confirmed that LPAR1 and LPAR2 were mainly expressed in RA FLS, and when LPAR1 was inhibited, tumor necrosis factor (TNF)induced FLS proliferation was also reduced [146]. Another study suggested that LPA-LPAR1 was involved in SF-stimulated hBMSC migration in RA patients [147].

\section{LPAR and Sjogren's syndrome}

Sjogren's syndrome (SS) is a chronic autoimmune disease that has not yet been developed to cure it, but studies have shown that treatment with the LPAR1/3 antagonist Ki16425 improves spontaneous development in SS and nonobese diabetic (NOD) mice in adoptive transfer models. SS. Tip LPA and its receptor may be valid targets for SS therapy [148].

\section{LPAR and asthma}

Asthma is one of the most commonplace lung diseases, and acute bronchoconstriction is one of the main reasons for hospitalization and sudden death from asthma. In animal models, LPA was found to trigger acute allergen and bradykinin-mediated bronchoconstriction by activating carotid body TRPV1 and LPA receptors, causing acute asthma symptoms. It was worth noting that this mechanism has not yet been confirmed in the human body, which can be used as a new research direction [149]. In a previous study, a mouse model of allergic asthma with $\mathrm{LPA}_{2}$ deficiency was found to be more severe than wild-type mice with pulmonary and systemic inflammation [150]. In another study, the role of LPAR2 in suppressing inflammation in asthma was also confirmed. When LPAR2 agonists were used, the inflammation of the lungs and airways of mice caused by allergen sensitization and challenge by HDM (dermatophagoides pteronyssinus) was significantly reduced. This may be related to reduced chemokine production and inhibition of cell migration [151].

\section{LPAR and liver regeneration}

The role of LPA and its receptors is essential in the overall changing process of liver disease. First, LPA can support the involvement of Rho-kinase by regulating cell morphology and attachment to the extracellular matrix, to reinforce the remodeling of collagen matrix by hepatic stellate cells (HSCs) [152]. Second, the more severe the liver damage, the higher the concentration of LPA in plasma [153]. Liver disease was a common digestive system disease, and severe liver diseases such as liver cancer have a poor prognosis. Liver resection or liver transplantation was an effective method for treating HCC. Using an enzyme-linked immunosorbent assay (ELISA), it was found that after partial hepatectomy (PHx), circulating LPA increased significantly after 72 hours, and LPAR1 increased in two stages of 12-24 hours and 48 hours-7 days, respectively. The LPAR1-stained cells are HSCs. Both LPAR3 mRNA and LPAR6 mRNA expression increased within 12 hours, but LPAR6 mRNA expression also increased significantly during the subsequent 48 hours to 7 day period. Moreover, LPAR6 was more widely stained than LPAR1 and LPAR3. These results suggest that LPA receptors (LPAR1, LPAR3, LPAR6) can promote liver regeneration after hepatectomy [128].

\section{Perspectives and future directions}

The growth factor-like lipid medium LPA acts as an effective signaling molecule that affects many physiological and pathological processes. So far, research on LPA receptors has progressed in many aspects, especially the most comprehensive study of $\mathrm{LPA}_{1}$ receptors, which of course was related to the broader expression of $\mathrm{LPA}_{1}$ receptors than other receptors. However, studies on non-EDG receptors, especially $\mathrm{LPA}_{6}$ receptors, are not comprehensive. It can be used as one of the future research directions. LPA signaling was associated with pathological responses, including conduction of neuropathic pain, promotion of tumorigenesis and metastasis, promotion of fibrosis, and promotion of atherosclerosis. The six G-protein coupled receptors that bind to it have become clear targets for drug development. Some drugs have entered clinical stages, such as the $\mathrm{LPA}_{1}$ receptor antagonists ONO7300243 and ONO-0300302 are used to treat benign prostatic hyperplasia and inhibit LPA-induced increases in intraurethral pressure in rats and dogs. The $\mathrm{LPA}_{1}$ receptor antagonist BMS986020 for idiopathic fibrosis has entered phase II clinical trials but has been discontinued due to noticeable side effects. The $\mathrm{LPA}_{1}$ receptor antagonist Debio-0716 can reduce distant metastasis and lymph node metastasis in breast cancer. The $\mathrm{LPA}_{1}$ receptor antagonist ONO-8430506 can lower tumor resistance and enhance azithromycin-induced tumor cell death. $\mathrm{LPA}_{1 / 3}$ receptor antagonist SAR100842 can treat systemic sclerosis [65,154]. In view of the wide-ranging role of LPA and its receptors in diseases, future research on drugs targeting LPA and its receptors will be of paramount importance. 


\section{Abbreviations}

LPA: lysophosphatidic acid; GPCRs: G-protein coupled receptors; LPAR: lysophosphatidic acid receptor; EDG: endothelial differentiation gene; ECL: extracellular loop; ICL: intracellular loop; VZ: ventricular zone; TMIII: transmembrane-spanning III; TMV: transmembrane-spanning $\mathrm{V}$; TMVII: transmembrane-spanning VII; VIC: valve interstitial cell; PDZ: PSD-95/DlgA/ZO-1; NHERF: $\mathrm{Na}^{+} / \mathrm{H}^{+}$ exchange regulatory factor; MAGI-2: inverted orientation-2; MAGI-3: inverted orientation-3; HCC: hepatocellular carcinoma; PI3K: phosphatidylinositol 3-kinase; PKCd: protein kinase Cd; STAT3: signal transducers and activators of transcription 3 (STAT3); PRG: PDZ-RhoGEF; LARG: leukemia-associated Rho GEF; SPC: smooth muscle progenitor cells; CPSP: central post-stroke pain; COX-2: cyclooxygenase-2; PGI2: prostacyclin; cAMP: cyclic adenosine monophosphate; YAP: Yes-associated protein; TAZ: transcriptional co-activator with PDZ-binding motif; TCR: T cell antigen receptor; ERK: extracellular regulated protein kinases; DRG: dorsal root ganglia; NHE3: $\mathrm{Na}^{+} / \mathrm{H}^{+}$Exchanger 3; PLD: phospholipase D; TRPA1: transient receptor potential ankyrin 1; TRPV1: transient receptor potential vanilloid 1; VEGF: vascular endothelial growth factor; IL: interleukin; EGFR: epidermal growth factor receptor; OSC: ovarian serous cystadenocarcinoma; ITH: intratumoral heterogeneity; BC: breast cancer; ATX: autotaxin; MAPK: mitogen-activated protein kinase; RNAi: RNA interference; cPKC: classical protein kinase C; NERF-2: $\mathrm{Na}^{+} / \mathrm{H}^{+}$exchange regulatory factor; PLC: phospholipase C; CARMA3: caspase recruit domain and MAGUK domain containing 3; MALT1: mucosa-associated lymphoid tissue 1; NF-kB: nuclear factor-kappa $\kappa B$; PKC 8 : protein kinase $C \delta$; GBM: Glioblastoma; PIT: photochemically induced thrombosis; CNS: central nervous system; PKD: protein kinase D; NP: neuropathic pain; CPZ: cuprizone; MS: multiple sclerosis; FH: fetal hydrocephalus; $\quad \mathrm{PHH}$ posthemorrhagic hydrocephalus; NPC: neural progenitor cells; BBB: blood-brain barrier; TCA: tricyclic antidepressant amitriptyline; AD: alzheimer's disease; CVD: cardiovascular disease; SMCs: smooth muscle cells; CXCL12: CXC motif ligand 12; HIF: hypoxia-inducible factor; DGPP: dioctylglycerol pyrophosphate; PA: dioctylphosphatidic acid; ADP: adenosine diphosphate; CAVS: calcified aortic stenosis; HF-HS: high-fat and high-sucrose; UUO: unilateral ureteral obstruction; TIF: ubulointerstitial fibrosis; RT: reverse transcription; PCR: polymerase chain reaction; CTGF: connective tissue growth factor; NTS: nephrotoxic serum; OxLDL: oxidative transformation of low-density lipoprotein; BAL: bronchoalveolar lavage; IPF: idiopathic pulmonary fibrosis; BALF: bronchoalveolar lavage fluid; FVC: forced vital capacity; TGF: transforming growth factor; BMSC: bone marrow-derived mesenchymal stem cells; ECM: extracellular matrix; JNK: c-Jun N-terminal kinase; APAP: acetaminophen; HCV: hepatitis $\mathrm{C}$ virus; TAA: thioacetamide; STZ: streptozotocin; PPARY: peroxisome proliferator-activated receptor $\gamma$; SS: Sjogren's syndrome; RA: Rheumatoid arthritis; FLS: fibroblast-like synoviocytes; NOD: nonobese diabetic; HSCs: hepatic stellate cells; ELISA: enzyme-linked immunosorbent assay; PHx: partial hepatectomy.

\section{Acknowledgements}

This work was supported by the National Natural Science Foundation of China (81873076), Shanghai Rising-Star Project (15QA1403500) and Shanghai Talents development fund Project (2017090).

\section{Competing Interests}

The authors have declared that no competing interest exists.

\section{References}

1. van Meeteren LA, Moolenaar WH. Regulation and biological activities of the autotaxin-LPA axis. Progress in Lipid Research. 2007;46(2):145-60.

2. Llona-Minguez S, Ghassemian A, Helleday T. Lysophosphatidic acid receptor (LPAR) modulators: The current pharmacological toolbox. Prog Lipid Res. 2015;58,51-75.

3. Yanagida K, Kurikawa $Y$, Shimizu T, Ishii S. Current progress in non-Edg family LPA receptor research. Biochim Biophys Acta. 2013;1831(1):33-41.

4. Peng WT, Sun WY, Li XR, Sun JC, Du JJ, Wei W. Emerging Roles of G Protein-Coupled Receptors in Hepatocellular Carcinoma. Int J Mol Sci. 2018;19(5).

5. Kihara Y, Maceyka M, Spiegel S, Chun J. Lysophospholipid receptor nomenclature review: IUPHAR Review 8. British journal of pharmacology. 2014;171(15):3575-94.

6. Mutoh T, Rivera R, Chun J. Insights into the pharmacological relevance of lysophospholipid receptors. British journal of pharmacology. 2012;165(4):829-44.

7. Yung YC, Stoddard NC, Chun J. LPA receptor signaling: pharmacology, physiology, and pathophysiology. Journal of lipid research. 2014;55(7):1192-214.

8. Hecht JH, Weiner JA, Post SR, Chun J. Ventricular zone gene-1 (vzg-1) encodes a lysophosphatidic acid receptor expressed in neurogenic regions of the developing cerebral cortex. The Journal of cell biology. 1996;135(4):1071-83.

9. Choi JW, Herr DR, Noguchi K, Yung YC, Lee CW, Mutoh T, et al. LPA receptors: subtypes and biological actions. Annu Rev Pharmacol Toxicol. 2010;50:157-86.

10. Contos JJ, Chun J. Complete cDNA sequence, genomic structure, and chromosomal localization of the LPA receptor gene, lpA1/vzg-1/Gpcr26. Genomics. 1998;51(3):364-78.

11. Murph MM, Nguyen GH, Radhakrishna H, Mills GB. Sharpening the edges of understanding the structure/function of the LPA1 receptor: expression in cancer and mechanisms of regulation. Biochim Biophys Acta. 2008;1781(9):547-57.

12. Chrencik JE, Roth CB, Terakado M, Kurata H, Omi R, Kihara Y, et al. Crystal Structure of Antagonist Bound Human Lysophosphatidic Acid Receptor 1. Cell. 2015;161(7):1633-43.

13. Shano S, Moriyama R, Chun J, Fukushima N. Lysophosphatidic acid stimulates astrocyte proliferation through LPA1. Neurochemistry International. 2008;52(1-2):216-20.

14. Subramanian P, Karshovska E, Reinhard P, Megens RTA, Zhou Z, Akhtar S, et al. Lysophosphatidic Acid Receptors LPA1 and LPA3 Promote CXCL12-Mediated Smooth Muscle Progenitor Cell Recruitment in Neointima Formation. Circulation Research. 2010;107(1):96-105.

15. Contos JJ, Chun J. Genomic characterization of the lysophosphatidic acid receptor gene, $\operatorname{lp}(\mathrm{A} 2) / \mathrm{Edg} 4$, and identification of a frameshift mutation in a previously characterized cDNA. Genomics. 2000;64(2):155-69.

16. Ishii I, Fukushima N, Ye X, Chun J. Lysophospholipid receptors: signaling and biology. Annu Rev Biochem. 2004;73:321-54. 
17. Lee SI, Ritter SL, Zhang H, Shim H, Hall RA, Yun CC. MAGI-3 competes with NHERF-2 to negatively regulate LPA2 receptor signaling in colon cancer cells. Gastroenterology. 2011;140(3):924-34.

18. Ren A, Moon C, Zhang W, Sinha C, Yarlagadda S, Arora K, et al. Asymmetrical macromolecular complex formation of lysophosphatidic acid receptor 2 (LPA2) mediates gradient sensing in fibroblasts. J Biol Chem. 2014;289(52):35757-69.

19. Tigyi GJ, Johnson LR, Lee SC, Norman DD, Szabo E, Balogh A, et al. Lysophosphatidic acid type 2 receptor agonists in targeted drug development offer broad therapeutic potential. Journal of lipid research. 2019;60(3):464-74.

20. Bandoh $\mathrm{K}$, Aoki J, Hosono $\mathrm{H}$, Kobayashi $\mathrm{S}$, Kobayashi $\mathrm{T}$, Murakami-Murofushi K, et al. Molecular cloning and characterization of a novel human G-protein-coupled receptor, EDG7, for lysophosphatidic acid. The Journal of biological chemistry. 1999;274(39):27776-85.

21. Chun J, Hla T, Lynch KR, Spiegel S, Moolenaar WH. International Union of Basic and Clinical Pharmacology. LXXVIII. Lysophospholipid receptor nomenclature. Pharmacol Rev. 2010;62(4):579-87.

22. Ishii I, Contos JJ, Fukushima N, Chun J. Functional comparisons of the lysophosphatidic acid receptors, LP(A1)/VZG-1/EDG-2, LP(A2)/EDG-4, and LP(A3)/EDG-7 in neuronal cell lines using a retrovirus expression system. Molecular pharmacology. 2000;58(5):895-902

23. Chan LC, Peters W, Xu Y, Chun J, Farese RV, Jr., Cases S. LPA3 receptor mediates chemotaxis of immature murine dendritic cells to unsaturated lysophosphatidic acid (LPA). J Leukoc Biol. 2007;82(5):1193-200.

24. Ueda H, Neyama H, Sasaki K, Miyama C, Iwamoto R. Lysophosphatidic acid LPA1 and LPA3 receptors play roles in the maintenance of late tissue plasminogen activator-induced central poststroke pain in mice. Neurobiol Pain. 2019;5:100020.

25. Shah BH, Catt KJ. Roles of LPA3 and COX-2 in implantation. Trends Endocrinol Metab. 2005;16(9):397-9.

26. Hama K, Aoki J. LPA(3), a unique G protein-coupled receptor for lysophosphatidic acid. Prog Lipid Res. 2010;49(4):335-42.

27. Noguchi K, Ishii S, Shimizu T. Identification of p2y9/GPR23 as a novel G protein-coupled receptor for lysophosphatidic acid, structurally distant from the Edg family. J Biol Chem. 2003;278(28):25600-6.

28. Li G, Mosier PD, Fang X, Zhang Y. Toward the three-dimensional structure and lysophosphatidic acid binding characteristics of the LPA(4)/p2y(9)/GPR23 receptor: a homology modeling study. J Mol Graph Model. 2009;28(1):70-9.

29. Yanagida K, Ishii S, Hamano F, Noguchi K, Shimizu T. LPA4/p2y9/GPR23 mediates rho-dependent morphological changes in a rat neuronal cell line. The Journal of biological chemistry. 2007;282(8):5814-24.

30. Lee CW, Rivera R, Dubin AE, Chun J. LPA(4)/GPR23 is a lysophosphatidic acid (LPA) receptor utilizing $\mathrm{G}(\mathrm{s})-, \mathrm{G}(\mathrm{q}) / \mathrm{G}(\mathrm{i})$-mediated calcium signaling and G(12/13)-mediated Rho activation. The Journal of biological chemistry. 2007;282(7):4310-7.

31. Rhee HJ, Nam JS, Sun Y, Kim MJ, Choi HK, Han DH, et al. Lysophosphatidic acid stimulates cAMP accumulation and cAMP response element-binding protein phosphorylation in immortalized hippocampal progenitor cells. Neuroreport. 2006;17(5):523-6.

32. Lee Z, Cheng CT, Zhang H, Subler MA, Wu J, Mukherjee A, et al. Role of LPA4/p2y9/GPR23 in negative regulation of cell motility. Mol Biol Cell. 2008;19(12):5435-45.

33. Takahashi K, Fukushima K, Onishi Y, Inui K, Node Y, Fukushima N, et al. Lysophosphatidic acid (LPA) signaling via LPA4 and LPA6 negatively regulates cell motile activities of colon cancer cells. Biochem Biophys Res Commun. 2017;483(1):652-7.

34. Sumida H, Noguchi K, Kihara Y, Abe M, Yanagida K, Hamano F, et al. LPA4 regulates blood and lymphatic vessel formation during mouse embryogenesis. Blood. 2010;116(23):5060-70.

35. Yasuda D, Kobayashi D, Akahoshi N, Ohto-Nakanishi T, Yoshioka K, Takuwa $\mathrm{Y}$, et al. Lysophosphatidic acid-induced YAP/TAZ activation promotes developmental angiogenesis by repressing Notch ligand Dll4. J Clin Invest. 2019;130.

36. He L, Wu MZ, Wang XB, Oiu XS, Wang EH, Wu GP. Tumor Suppressor LKB1 inhibits both the mRNA Expression and the Amplification of hTERC by the Phosphorylation of YAP in Lung Cancer Cells. J Cancer. 2019;10(16):3632-8.

37. Dong $\mathrm{L}$, Lin $\mathrm{F}, \mathrm{Wu} \mathrm{W}$, Huang $\mathrm{W}$, Cai Z. Transcriptional cofactor Mask2 is required for YAP-induced cell growth and migration in bladder cancer cell. J Cancer. 2016;7(14):2132-8.

38. Liu $Y$, Ren M, Tan X, Hu L. Distinct Changes in the Expression TAZ are Associated with Normal Cervix and Human Cervical Cancer. J Cancer. 2018;9(22):4263-70.

39. Mansell JP, Barbour M, Moore C, Nowghani M, Pabbruwe M, Sjostrom T, et al. The synergistic effects of lysophosphatidic acid receptor agonists and calcitriol on MG63 osteoblast maturation at titanium and hydroxyapatite surfaces. Biomaterials. 2010;31(2):199-206.

40. Lee CW, Rivera R, Gardell S, Dubin AE, Chun J. GPR92 as a new G12/13- and Gq-coupled lysophosphatidic acid receptor that increases cAMP, LPA5. J Biol Chem. 2006;281(33):23589-97.

41. Lin S, Yeruva S, He P, Singh AK, Zhang H, Chen M, et al. Lysophosphatidic acid stimulates the intestinal brush border $\mathrm{Na}(+) / \mathrm{H}(+)$ exchanger 3 and fluid absorption via LPA(5) and NHERF2. Gastroenterology. 2010;138(2):649-58.
42. Murai N, Hiyama $\mathrm{H}$, Kiso $\mathrm{T}$, Sekizawa $\mathrm{T}$, Watabiki $\mathrm{T}$, Oka $\mathrm{H}$, et al. Analgesic effects of novel lysophosphatidic acid receptor 5 antagonist AS2717638 in rodents. Neuropharmacology. 2017;126:97-107.

43. Mathew D, Kremer KN, Strauch P, Tigyi G, Pelanda R, Torres RM. LPA5 Is an Inhibitory Receptor That Suppresses CD8 T-Cell Cytotoxic Function via Disruption of Early TCR Signaling. Front Immunol. 2019;10:1159.

44. Jenkin KA, He P, Yun CC. Expression of lysophosphatidic acid receptor 5 is necessary for the regulation of intestinal $\mathrm{Na} / \mathrm{H}$ exchanger 3 by lysophosphatidic acid in vivo. American journal of physiology Gastrointestinal and liver physiology. 2018;315(4): G433-G442.

45. Kittaka H, Uchida K, Fukuta N, Tominaga M. Lysophosphatidic acid-induced itch is mediated by signalling of LPA5 receptor, phospholipase D and TRPA1/TRPV1. J Physiol. 2017;595(8):2681-98.

46. Taniguchi R, Inoue A, Sayama M, Uwamizu A, Yamashita K, Hirata K, et al. Structural insights into ligand recognition by the lysophosphatidic acid receptor LPA6. Nature. 2017;548(7667):356-60.

47. Lee M, Choi S, Hallden G, Yo SJ, Schichnes D, Aponte GW. P2Y5 is a G(alpha)i, $\mathrm{G}($ alpha)12/13 G protein-coupled receptor activated by lysophosphatidic acid that reduces intestinal cell adhesion. Am J Physiol Gastrointest Liver Physiol. 2009;297(4):G641-54

48. Yanagida K, Masago K, Nakanishi H, Kihara Y, Hamano F, Tajima Y, et al. Identification and characterization of a novel lysophosphatidic acid receptor, p2y5/LPA6. J Biol Chem. 2009;284(26):17731-41.

49. Takara K, Eino D, Ando K, Yasuda D, Naito $H$, Tsukada $Y$, et al Lysophosphatidic Acid Receptor 4 Activation Augments Drug Delivery in Tumors by Tightening Endothelial Cell-Cell Contact. Cell Rep. 2017;20(9):2072-86

50. Pasternack SM, von Kügelgen I, Aboud KA, Lee Y-A, Rüschendorf F, Voss K, et al. G protein-coupled receptor P2Y5 and its ligand LPA are involved in maintenance of human hair growth. Nature Genetics. 2008;40(3):329-34.

51. Folkman J. A new link in ovarian cancer angiogenesis: lysophosphatidic acid and vascular endothelial growth factor expression. Journal of the National Cancer Institute. 2001;93(10):734-5.

52. $\mathrm{Hu} \mathrm{YL}$, Tee MK, Goetzl EJ, Auersperg N, Mills GB, Ferrara N, et al. Lysophosphatidic acid induction of vascular endothelial growth factor expression in human ovarian cancer cells. Journal of the National Cancer Institute. 2001;93(10):762-8.

53. Mills GB, Moolenaar WH. The emerging role of lysophosphatidic acid in cancer. Nat Rev Cancer. 2003;3(8):582-91.

54. Cui R, Cao G, Bai H, Zhang Z. LPAR1 regulates the development of intratumoral heterogeneity in ovarian serous cystadenocarcinoma by activating the PI3K/AKT signaling pathway. Cancer Cell Int. 2019;19:201.

55. Hu YL, Albanese C, Pestell RG, Jaffe RB. Dual mechanisms for lysophosphatidic acid stimulation of human ovarian carcinoma cells. Journal of the National Cancer Institute. 2003:95(10):733-40.

56. Yu S, Murph MM, Lu Y, Liu S, Hall HS, Liu J, et al. Lysophosphatidic acid receptors determine tumorigenicity and aggressiveness of ovarian cancer cells. J Natl Cancer Inst. 2008;100(22):1630-42.

57. Jeong KJ, Park SY, Seo JH, Lee KB, Choi WS, Han JW, et al. Lysophosphatidic acid receptor 2 and $\mathrm{Gi} / \mathrm{Src}$ pathway mediate cell motility through cyclooxygenase 2 expression in CAOV-3 ovarian cancer cells. Exp Mol Med. 2008;40(6):607-16.

58. Ha JH, Radhakrishnan R, Jayaraman M, Yan M, Ward JD, Fung KM, et al. LPA Induces Metabolic Reprogramming in Ovarian Cancer via a Pseudohypoxic Response. Cancer Res. 2018;78(8):1923-34.

59. Li GC, Qin XL, Song HH, Li YN, Qiu YY, Cui SC, et al. Upregulated microRNA-15b alleviates ovarian cancer through inhitbition of the PI3K/Akt pathway by targeting LPAR3. J Cell Physiol. 2019; 234(12):22331-22342.

60. Panupinthu N, Lee HY, Mills GB. Lysophosphatidic acid production and action: critical new players in breast cancer initiation and progression. Br J Cancer. 2010;102(6):941-6.

61. Marshall JC, Collins JW, Nakayama J, Horak CE, Liewehr DJ, Steinberg SM, et al. Effect of inhibition of the lysophosphatidic acid receptor 1 on metastasis and metastatic dormancy in breast cancer. J Natl Cancer Inst. 2012;104(17):1306-19.

62. Liu S, Umezu-Goto M, Murph M, Lu Y, Liu W, Zhang F, et al. Expression of autotaxin and lysophosphatidic acid receptors increases mammary tumorigenesis, invasion, and metastases. Cancer Cell. 2009;15(6):539-50.

63. $\mathrm{Li} \mathrm{M}$, Xiao D, Zhang $\mathrm{J}, \mathrm{Qu} \mathrm{H}$, Yang $\mathrm{Y}$, Yan $\mathrm{Y}$, et al. Expression of LPA2 is associated with poor prognosis in human breast cancer and regulates HIF-1alpha expression and breast cancer cell growth. Oncol Rep. 2016;36(6):3479-87.

64. Popnikolov NK, Dalwadi BH, Thomas JD, Johannes GJ, Imagawa WT. Association of autotaxin and lysophosphatidic acid receptor 3 with aggressiveness of human breast carcinoma. Tumour Biol. 2012;33(6):2237-43.

65. Wang J, Sun Y, Qu J, Yan Y, Yang Y, Cai H. Roles of LPA receptor signaling in breast cancer. Expert Rev Mol Diagn. 2016;16(10):1103-11.

66. Qiu J, Xue X, Hu C, Xu H, Kou D, Li R, et al. Comparison of Clinicopathological Features and Prognosis in Triple-Negative and Non-Triple Negative Breast Cancer. J Cancer. 2016;7(2):167-73.

67. Tao K, Guo S, Chen R, Yang C, Jian L, Yu H, et al. Lysophosphatidic Acid Receptor 6 (LPAR6) Expression and Prospective Signaling Pathway Analysis in Breast Cancer. Mol Diagn Ther. 2019;23(1):127-38.

68. Shida D, Kitayama J, Yamaguchi H, Okaji Y, Tsuno NH, Watanabe T, et al. Lysophosphatidic acid (LPA) enhances the metastatic potential of human 
colon carcinoma DLD1 cells through LPA1. Cancer research. 2003;63(7):1706-11

69. Yun CC, Sun H, Wang D, Rusovici R, Castleberry A, Hall RA, et al. LPA2 receptor mediates mitogenic signals in human colon cancer cells. Am J Physiol Cell Physiol. 2005;289(1):C2-11.

70. Lin S, Wang D, Iyer S, Ghaleb AM, Shim H, Yang VW, et al. The absence of LPA2 attenuates tumor formation in an experimental model of colitis-associated cancer. Gastroenterology. 2009;136(5):1711-20.

71. Yang M, Zhong WW, Srivastava N, Slavin A, Yang J, Hoey T, et al. G protein-coupled lysophosphatidic acid receptors stimulate proliferation of colon cancer cells through the \{beta\}-catenin pathway. Proceedings of the National Academy of Sciences of the United States of America. 2005;102(17):6027-32

72. Lee SC, Fujiwara Y, Liu J, Yue J, Shimizu Y, Norman DD, et al. Autotaxin and LPA1 and LPA5 receptors exert disparate functions in tumor cells versus the host tissue microenvironment in melanoma invasion and metastasis. Mol Cancer Res. 2015;13(1):174-85.

73. Park SY, Jeong KJ, Panupinthu N, Yu S, Lee J, Han JW, et al. Lysophosphatidic acid augments human hepatocellular carcinoma cell invasion through LPA1 receptor and MMP-9 expression. Oncogene. 2010;30(11):1351-9.

74. Zuckerman V, Sokolov E, Swet JH, Ahrens WA, Showlater V, Iannitti DA, et al. Expression and function of lysophosphatidic acid receptors (LPARs) 1 and 3 in human hepatic cancer progenitor cells. Oncotarget. 2016;7(3):2951-67.

75. Okabe K, Kato K, Teranishi M, Okumura M, Fukui R, Mori T, et al. Induction of lysophosphatidic acid receptor-3 by 12-O-tetradecanoylphorbol-13-acetate stimulates cell migration of rat liver cells. Cancer Lett. 2011;309(2):236-42.

76. Mazzocca A, Dituri F, De Santis F, Filannino A, Lopane C, Betz RC, et al. Lysophosphatidic acid receptor LPAR6 supports the tumorigenicity of hepatocellular carcinoma. Cancer Res. 2015;75(3):532-43.

77. Sokolov E, Eheim AL, Ahrens WA, Walling TL, Swet JH, McMillan MT, et al. Lysophosphatidic acid receptor expression and function in human hepatocellular carcinoma. J Surg Res. 2013;180(1):104-13.

78. Lopane C, Agosti P, Gigante I, Sabba C, Mazzocca A. Implications of the lysophosphatidic acid signaling axis in liver cancer. Biochim Biophys Acta Rev Cancer. 2017;1868(1):277-82

79. Enooku K, Uranbileg B, Ikeda H, Kurano M, Sato M, Kudo H, et al. Higher LPA2 and LPA6 mRNA Levels in Hepatocellular Carcinoma Are Associated with Poorer Differentiation, Microvascular Invasion and Earlier Recurrence with Higher Serum Autotaxin Levels. PLoS One. 2016;11(9):e0161825.

80. Fukushima K, Takahashi K, Yamasaki E, Onishi Y, Fukushima N, Honoki K, et al. Lysophosphatidic acid signaling via LPA1 and LPA3 regulates cellular functions during tumor progression in pancreatic cancer cells. Exp Cell Res. 2017;352(1):139-45

81. Komachi M, Tomura H, Malchinkhuu E, Tobo M, Mogi C, Yamada T, et al. LPA1 receptors mediate stimulation, whereas LPA2 receptors mediate inhibition, of migration of pancreatic cancer cells in response to lysophosphatidic acid and malignant ascites. Carcinogenesis. 2009;30(3):457-65.

82. Fukushima K, Otagaki S, Takahashi K, Minami K, Ishimoto K, Fukushima N, et al. Promotion of cell-invasive activity through the induction of LPA receptor-1 in pancreatic cancer cells. J Recept Signal Transduct Res. 2018:38(4):367-71.

83. Komachi M, Sato K, Tobo M, Mogi C, Yamada T, Ohta H, et al. Orally active lysophosphatidic acid receptor antagonist attenuates pancreatic cancer invasion and metastasis in vivo. Cancer Sci. 2012;103(6):1099-104.

84. Yang S, Zhang L, Purohit V, Shukla SK, Chen X, Yu F, et al. Active YAP promotes pancreatic cancer cell motility, invasion and tumorigenesis in a mitotic phosphorylation-dependent manner through LPAR3. Oncotarget. 2015;6(34):36019-31.

85. Valdes-Rives SA, Gonzalez-Arenas A. Autotaxin-Lysophosphatidic Acid: From Inflammation to Cancer Development. Mediators Inflamm. 2017;2017:9173090

86. Valdés-Rives SA, de la Fuente-Granada M, Velasco-Velázquez MA, González-Flores O, González-Arenas A. LPA1 receptor activation induces PKCa nuclear translocation in glioblastoma cells. The International Journal of Biochemistry \& Cell Biology. 2019;110:91-102.

87. Jongsma M, Matas-Rico E, Rzadkowski A, Jalink K, Moolenaar WH. LPA is a chemorepellent for B16 melanoma cells: action through the cAMP-elevating LPA5 receptor. PLoS One. 2011;6(12):e29260.

88. Altman MK, Gopal V, Jia W, Yu S, Hall H, Mills GB, et al. Targeting melanoma growth and viability reveals dualistic functionality of the phosphonothionate analogue of carba cyclic phosphatidic acid. Mol Cancer. 2010;9:140.

89. Murph MM, Hurst-Kennedy J, Newton V, Brindley DN, Radhakrishna H. Lysophosphatidic acid decreases the nuclear localization and cellular abundance of the p53 tumor suppressor in A549 lung carcinoma cells. Mol Cancer Res. 2007;5(11):1201-11.

90. Hayashi M, Okabe K, Yamawaki Y, Teranishi M, Honoki K, Mori T, et al. Loss of lysophosphatidic acid receptor-3 enhances cell migration in rat lung tumor cells. Biochem Biophys Res Commun. 2011:405(3):450-4.

91. Yamada T, Obo Y, Furukawa M, Hotta M, Yamasaki A, Honoki K, et al. Mutations of lysophosphatidic acid receptor-1 gene during progression of lung tumors in rats. Biochem Biophys Res Commun. 2009;378(3):424-7.

92. Magkrioti C, Oikonomou N, Kaffe E, Mouratis MA, Xylourgidis N, Barbayianni I, et al. The Autotaxin-Lysophosphatidic Acid Axis Promotes Lung Carcinogenesis. Cancer Res. 2018;78(13):3634-44.
93. Inoue $\mathrm{M}$, Rashid $\mathrm{MH}$, Fujita $\mathrm{R}$, Contos JJ, Chun J, Ueda $\mathrm{H}$. Initiation of neuropathic pain requires lysophosphatidic acid receptor signaling. Nat Med. 2004;10(7):712-8

94. Velasco M, O'Sullivan C, Sheridan GK. Lysophosphatidic acid receptors (LPARs): Potential targets for the treatment of neuropathic pain. Neuropharmacology. 2017;113(Pt B):608-17.

95. Plastira I, Bernhart E, Goeritzer M, DeVaney T, Reicher H, Hammer A, et al. Lysophosphatidic acid via LPA-receptor 5/protein kinase D-dependent pathways induces a motile and pro-inflammatory microglial phenotype. Journal of neuroinflammation. 2017;14(1):253.

96. Tsukahara R, Yamamoto S, Yoshikawa K, Gotoh M, Tsukahara T, Neyama H, et al. LPA5 signaling is involved in multiple sclerosis-mediated neuropathic pain in the cuprizone mouse model. Journal of pharmacological sciences. 2018;136(2):93-6.

97. Yung YC, Mutoh T, Lin ME, Noguchi K, Rivera RR, Choi JW, et al. Lysophosphatidic acid signaling may initiate fetal hydrocephalus. Sci Transl Med. 2011;3(99):99ra87.

98. Park R, Moon UY, Park JY, Hughes LJ, Johnson RL, Cho S-H, et al. Yap is required for ependymal integrity and is suppressed in LPA-induced hydrocephalus. Nature Communications. 2016;7(1): 10329.

99. Lummis NC, Sánchez-Pavón P, Kennedy G, Frantz AJ, Kihara Y, Blaho VA, et al. LPA overactivation induces neonatal posthemorrhagic hydrocephalus through ependymal loss and ciliary dysfunction. Sci Adv. 2019;5(10):eaax2011.

100. Herr DR, Chew WS, Satish RL, Ong WY. Pleotropic Roles of Autotaxin in the Nervous System Present Opportunities for the Development of Novel Therapeutics for Neurological Diseases. Molecular neurobiology. 2020; 57(1):372-392.

101. Masago K, Kihara Y, Yanagida K, Hamano F, Nakagawa S, Niwa M, et al. Lysophosphatidic acid receptor, LPA6, regulates endothelial blood-brain barrier function: Implication for hepatic encephalopathy. Biochem Biophys Res Commun. 2018;501(4):1048-54.

102. Banks DB, Chan GN, Evans RA, Miller DS, Cannon RE. Lysophosphatidic acid and amitriptyline signal through LPA1R to reduce P-glycoprotein transport at the blood-brain barrier. J Cereb Blood Flow Metab. 2018;38(5):857-68.

103. Ramesh S, Govindarajulu M, Suppiramaniam V, Moore T, Dhanasekaran M. Autotaxin-Lysophosphatidic Acid Signaling in Alzheimer's Disease. Int J Mol Sci. 2018;19(7)

104. Frisca F, Sabbadini RA, Goldshmit Y, Pébay A. Biological effects of lysophosphatidic acid in the nervous system. International review of cell and molecular biology. 2012;296:273-322.

105. Jiang L, Krumholz HM, Li X, Li J, Hu S. Achieving best outcomes for patients with cardiovascular disease in China by enhancing the quality of medical care and establishing a learning health-care system. The Lancet. 2015;386(10002):1493-505

106. Panchatcharam M, Miriyala S, Yang F, Rojas M, End C, Vallant C, et al. Lysophosphatidic acid receptors 1 and 2 play roles in regulation of vascular injury responses but not blood pressure. Circ Res. 2008;103(6):662-70.

107. Zhou Z, Subramanian P, Sevilmis G, Globke B, Soehnlein O, Karshovska E, et al. Lipoprotein-derived lysophosphatidic acid promotes atherosclerosis by releasing CXCL1 from the endothelium. Cell Metab. 2011;13(5):592-600.

108. Kritikou E, van Puijvelde GH, van der Heijden T, van Santbrink PJ, Swart M, Schaftenaar FH, et al. Inhibition of lysophosphatidic acid receptors 1 and 3 attenuates atherosclerosis development in LDL-receptor deficient mice. Sci Rep. 2016;6:37585

109. Rother E, Brandl R, Baker DL, Goyal P, Gebhard H, Tigyi G, et al. Subtype-selective antagonists of lysophosphatidic Acid receptors inhibit platelet activation triggered by the lipid core of atherosclerotic plaques. Circulation. 2003;108(6):741-7.

110. Schober A, Siess W. Lysophosphatidic acid in atherosclerotic diseases. Br J Pharmacol. 2012;167(3):465-82.

111. Cho J, Mosher DF. Enhancement of thrombogenesis by plasma fibronectin cross-linked to fibrin and assembled in platelet thrombi. Blood. 2006;107(9):3555-63.

112. Nsaibia MJ, Boulanger MC, Bouchareb R, Mkannez G, Le Quang K, Hadji F, et al. OxLDL-derived lysophosphatidic acid promotes the progression of aortic valve stenosis through a LPAR1-RhoA-NF-kB pathway. Cardiovascular research. 2017;113(11):1351-63.

113. Sakai N, Chun J, Duffield JS, Wada T, Luster AD, Tager AM. LPA1-induced cytoskeleton reorganization drives fibrosis through CTGF-dependent fibroblast proliferation. FASEB J. 2013;27(5):1830-46.

114. Pradere JP, Klein J, Gres S, Guigne C, Neau E, Valet P, et al. LPA1 receptor activation promotes renal interstitial fibrosis. J Am Soc Nephrol. 2007;18(12):3110-8

115. Sakai N, Bain G, Furuichi K, Iwata Y, Nakamura M, Hara A, et al. The involvement of autotaxin in renal interstitial fibrosis through regulation of fibroblast functions and induction of vascular leakage. Sci Rep. 2019:9(1):7414.

116. Sakai N, Chun J, Duffield JS, Lagares D, Wada T, Luster AD, et al. Lysophosphatidic acid signaling through its receptor initiates profibrotic epithelial cell fibroblast communication mediated by epithelial cell derived connective tissue growth factor. Kidney Int. 2017;91(3):628-41.

117. Geng H, Lan R, Singha PK, Gilchrist A, Weinreb PH, Violette SM, et al. Lysophosphatidic acid increases proximal tubule cell secretion of profibrotic cytokines PDGF-B and CTGF through LPA2- and Galphaq-mediated Rho and alphavbeta6 integrin-dependent activation of TGF-beta. Am J Pathol. 2012;181(4):1236-49. 
118. Pradere JP, Gonzalez J, Klein J, Valet P, Gres $S$, Salant D, et al Lysophosphatidic acid and renal fibrosis. Biochim Biophys Acta. 2008;1781(9):582-7.

119. Mirzoyan K, Baiotto A, Dupuy A, Marsal D, Denis C, Vinel C, et al. Increased urinary lysophosphatidic acid in mouse with subtotal nephrectomy: potential involvement in chronic kidney disease. J Physiol Biochem. 2016;72(4):803-12.

120. Georas SN, Berdyshev E, Hubbard W, Gorshkova IA, Usatyuk PV, Saatian B, et al. Lysophosphatidic acid is detectable in human bronchoalveolar lavage fluids at baseline and increased after segmental allergen challenge. Clin Exp Allergy. 2007;37(3):311-22.

121. Tager AM, LaCamera P, Shea BS, Campanella GS, Selman M, Zhao Z, et al. The lysophosphatidic acid receptor LPA1 links pulmonary fibrosis to lung injury by mediating fibroblast recruitment and vascular leak. Nat Med. 2008;14(1):45-54.

122. Funke M, Zhao Z, Xu Y, Chun J, Tager AM. The Lysophosphatidic Acid Receptor LPA1Promotes Epithelial Cell Apoptosis after Lung Injury. American Journal of Respiratory Cell and Molecular Biology. 2012;46(3):355-64.

123. Swaney JS, Chapman C, Correa LD, Stebbins KJ, Bundey RA, Prodanovich PC, et al. A novel, orally active LPA(1) receptor antagonist inhibits lung fibrosis in the mouse bleomycin model. Br J Pharmacol. 2010;160(7):1699-713.

124. Palmer SM, Snyder L, Todd JL, Soule B, Christian R, Anstrom K, et al. Randomized, Double-Blind, Placebo-Controlled, Phase 2 Trial of BMS-986020, a Lysophosphatidic Acid Receptor Antagonist for the Treatment of Idiopathic Pulmonary Fibrosis. Chest. 2018;154(5):1061-9.

125. Huang LS, Fu P, Patel P, Harijith A, Sun T, Zhao Y, et al. Lysophosphatidic acid receptor-2 deficiency confers protection against bleomycin-induced lung injury and fibrosis in mice. Am J Respir Cell Mol Biol. 2013;49(6):912-22.

126. Gan L, Xue JX, Li X, Liu DS, Ge Y, Ni PY, et al. Blockade of lysophosphatidic acid receptors LPAR1/3 ameliorates lung fibrosis induced by irradiation. Biochem Biophys Res Commun. 2011;409(1):7-13.

127. Tang N, Zhao Y, Feng R, Liu Y, Wang S, Wei W, et al. Lysophosphatidic acid accelerates lung fibrosis by inducing differentiation of mesenchymal stem cells into myofibroblasts. J Cell Mol Med. 2014;18(1):156-69.

128. Simo KA, Niemeyer DJ, Hanna EM, Swet JH, Thompson KJ, Sindram D, et al. Altered lysophosphatidic acid (LPA) receptor expression during hepatic regeneration in a mouse model of partial hepatectomy. HPB (Oxford). 2014;16(6):534-42.

129. Farquhar MJ, Humphreys IS, Rudge SA, Wilson GK, Bhattacharya B, Ciaccia $\mathrm{M}$, et al. Autotaxin-lysophosphatidic acid receptor signalling regulates hepatitis C virus replication. J Hepatol. 2017;66(5):919-29.

130. Eraky SM, El-Mesery M, El-Karef A, Eissa LA, El-Gayar AM. Silymarin and caffeine combination ameliorates experimentally-induced hepatic fibrosis through down-regulation of LPAR1 expression. Biomed Pharmacother. 2018;101:49-57.

131. Nakagawa H, Ikeda H, Nakamura K, Ohkawa R, Masuzaki R, Tateishi R, et al. Autotaxin as a novel serum marker of liver fibrosis. Clin Chim Acta. 2011:412(13-14):1201-6.

132. Castelino FV, Seiders J, Bain G, Brooks SF, King CD, Swaney JS, et al. Amelioration of dermal fibrosis by genetic deletion or pharmacologic antagonism of lysophosphatidic acid receptor 1 in a mouse model of scleroderma. Arthritis Rheum. 2011;63(5):1405-15.

133. Zuo C, Li X, Huang J, Chen D, Ji K, Yang Y, et al. Osteoglycin attenuates cardiac fibrosis by suppressing cardiac myofibroblast proliferation and migration through antagonizing lysophosphatidic acid $3 /$ matrix metalloproteinase 2/epidermal growth factor receptor signalling. Cardiovasc Res. 2018;114(5):703-12

134. Rancoule C, Viaud M, Gres S, Viguerie N, Decaunes P, Bouloumie A, et al. Pro-fibrotic activity of lysophosphatidic acid in adipose tissue: in vivo and in vitro evidence. Biochim Biophys Acta. 2014;1841(1):88-96.

135. Yea K, Kim J, Lim S, Park HS, Park KS, Suh PG, et al. Lysophosphatidic acid regulates blood glucose by stimulating myotube and adipocyte glucose uptake. J Mol Med (Berl). 2008;86(2):211-20.

136. He P, Zhao L, Zhu L, Weinman EJ, De Giorgio R, Koval M, et al. Restoration of $\mathrm{Na}+\mathrm{H}+$ exchanger NHE3-containing macrocomplexes ameliorates diabetes-associated fluid loss. J Clin Invest. 2015;125(9):3519-31.

137. Li HY, Oh YS, Choi JW, Jung JY, Jun HS. Blocking lysophosphatidic acid receptor 1 signaling inhibits diabetic nephropathy in $\mathrm{db} / \mathrm{db}$ mice. Kidney Int. 2017;91(6):1362-73

138. Lee JH, Kim D, Oh YS, Jun HS. Lysophosphatidic Acid Signaling in Diabetic Nephropathy. Int J Mol Sci. 2019;20(11)

139. Zhang MZ, Wang $X$, Yang $H$, Fogo AB, Murphy BJ, Kaltenbach $R$, et al. Lysophosphatidic Acid Receptor Antagonism Protects against Diabetic Nephropathy in a Type 2 Diabetic Model. J Am Soc Nephrol. 2017;28(11):3300-11.

140. Lee JH, Sarker MK, Choi H, Shin D, Kim D, Jun HS. Lysophosphatidic acid receptor 1 inhibitor, AM095, attenuates diabetic nephropathy in mice by downregulation of TLR4/NF-kappaB signaling and NADPH oxidase. Biochim Biophys Acta Mol Basis Dis. 2019:1865(6):1332-40.

141. D'Souza K, Paramel GV, Kienesberger PC. Lysophosphatidic Acid Signaling in Obesity and Insulin Resistance. Nutrients. 2018;10(4):399.

142. Dusaulcy R, Daviaud D, Pradère JP, Grès S, Valet P, Saulnier-Blache JS Altered food consumption in mice lacking lysophosphatidic acid receptor-1. J Physiol Biochem. 2009;65(4):345-50.
143. Miyabe Y, Miyabe C, Iwai Y, Takayasu A, Fukuda S, Yokoyama W, et al. Necessity of lysophosphatidic acid receptor 1 for development of arthritis. Arthritis Rheum. 2013;65(8):2037-47.

144. Orosa B, Garcia S, Martinez P, Gonzalez A, Gomez-Reino JJ, Conde C. Lysophosphatidic acid receptor inhibition as a new multipronged treatment for rheumatoid arthritis. Ann Rheum Dis. 2014;73(1):298-305.

145. Miyabe Y, Miyabe C, Iwai Y, Yokoyama W, Sekine C, Sugimoto K, et al Activation of fibroblast-like synoviocytes derived from rheumatoid arthritis via lysophosphatidic acid-lysophosphatidic acid receptor 1 cascade. Arthritis research \& therapy. 2014;16(5):461.

146. Orosa B, Gonzalez A, Mera A, Gomez-Reino JJ, Conde C. Lysophosphatidic acid receptor 1 suppression sensitizes rheumatoid fibroblast-like synoviocytes to tumor necrosis factor-induced apoptosis. Arthritis Rheum. 2012;64(8):2460-70

147. Song HY, Lee MJ, Kim MY, Kim KH, Lee IH, Shin SH, et al. Lysophosphatidic acid mediates migration of human mesenchymal stem cells stimulated by synovial fluid of patients with rheumatoid arthritis. Biochimica et Biophysica Acta (BBA) - Molecular and Cell Biology of Lipids. 2010;1801(1):23-30.

148. Park E, Kim D, Lee SM, Jun HS. Inhibition of lysophosphatidic acid receptor ameliorates Sjögren's syndrome in NOD mice. Oncotarget. 2017:8(16):27240-51.

149. Jendzjowsky NG, Roy A, Barioni NO, Kelly MM, Green FHY, Wyatt CN, et al. Preventing acute asthmatic symptoms by targeting a neuronal mechanism involving carotid body lysophosphatidic acid receptors. Nat Commun. 2018;9(1):4030.

150. Emo J, Meednu N, Chapman TJ, Rezaee F, Balys M, Randall T, et al. Lpa2 is a negative regulator of both dendritic cell activation and murine models of allergic lung inflammation. J Immunol. 2012;188(8):3784-90.

151. Knowlden SA, Hillman SE, Chapman TJ, Patil R, Miller DD, Tigyi G, et al. Novel Inhibitory Effect of a Lysophosphatidic Acid 2 Agonist on Allergen-Driven Airway Inflammation. Am J Respir Cell Mol Biol. 2016;54(3):402-9.

152. Yanase M, Ikeda H, Matsui A, Maekawa H, Noiri E, Tomiya T, et al. Lysophosphatidic acid enhances collagen gel contraction by hepatic stellate cells: association with rho-kinase. Biochem Biophys Res Commun. 2000;277(1):72-8

153. Watanabe N, Ikeda H, Nakamura K, Ohkawa R, Kume Y, Tomiya T, et al. Plasma lysophosphatidic acid level and serum autotaxin activity are increased in liver injury in rats in relation to its severity. Life Sci. 2007;81(12):1009-15.

154. Zhao Y, Hasse S, Zhao C, Bourgoin SG. Targeting the autotaxin Lysophosphatidic acid receptor axis in cardiovascular diseases. Biochemical Pharmacology. 2019;164:74-81. 